\title{
Culto Evangélico: Identificación, localización y caracterización en la segunda franja residencial (SFR) de Río Gallegos
}

\author{
Evangelical Worship: Identification, localization and characterization in Río Gallegos' \\ second residential strip (SRS)
}

\author{
Federico A. Huenchor, Mónica V. Norambuena, Alicia P. Cáceres \\ fedde.h29@hotmail.com,mnorambuena@uarg.unpa.edu.ar, acaceres@uarg.edu.ar \\ Grupo Z Terra Cognita \\ Instituto de Ciencias del Ambiente, Sustentabilidad y Recursos Naturales \\ Unidad Académica Río Gallegos, Universidad Nacional de la Patagonia Austral \\ Piloto Lero Rivero y Avenida Gobernador Gregores - Río Gallegos - Santa Cruz - Argentina
}

Recibido: 02/04/2020. Aceptado: 11/09/2020

\section{RESUMEN}

El presente Informe Científico-Técnico, perteneciente a una Beca de Investigación para Alumnos Avanzados de la UNPA, se enmarca en el PI 29 A/427-1 "La Geografía de las Religiones en el ejido municipal de Río Gallegos en el año 2018. La Geografía Cultural en la Patagonia austral extraandina". Teóricamente, pertenece a la Geografía Cultural Renovada en general y en particular a la Geografía de las Religiones, históricamente estudiadas desde la descripción y en sus características más básicas; actualmente se estudian integradas al territorio y sus transformaciones a diferentes escalas. Son escasas las investigaciones relacionadas a Río Gallegos, por esto la beca tiene como objetivos, en primer lugar, relevar y analizar bibliografía específica sobre la Geografía Cultural y la Geografía de las Religiones en particular. El segundo, identificar, caracterizar y cartografiar manifestaciones culturales religiosas relacionadas al culto evangélico en la Segunda Franja Residencial de Río Gallegos. Metodológicamente, se relevó, leyó comprensivamente y analizó bibliografía específica; se realizó una salida de campo para identificar y localizar las manifestaciones culturales religiosas evangélicas en la SFR, que fueron representadas cartográficamente con la ayuda de un SIG como herramienta principal y se realizó cartografía temática con dicho programa. Los resultados permitiran caracterizar las manifestaciones culturales, según las denominaciones de las iglesias evangélicas, además de aportar teórica y metodológicamente al PI 29 A/427-1 y a la formación en investigación del becario.

Palabras clave: Patagonia austral; religión; cristianismo; ejido municipal; siglo XXI.

\begin{abstract}
This report, itself an investigation scholarship directed to UNPA's advanced students, belongs to IP 29 A/427-1 'Religious geography in Río Gallegos' municipal land during 2018. Cultural geography in southern extra-Andean Patagonia'. Theoretically, it belongs to the Renewed Cultural Geography in general, and to the Religious Geography in particular, which historically speaking has been studied in a descriptive sense and in its most basic characteristics; nowadays they are being studied in relation to territory and the transformations taking place at different scales. Investigations related to Río Gallegos are scarce, hence, it's first purpose is to gather and analyze literature related to Cultural
\end{abstract}


Geography and Religious Geography; and it's second purpose is to identify, characterize and to create cartography about the evangelical cultural manifestations taking place inside Río Gallegos' SRS. In relation to this work's methodology, specific literature was read and analyzed thoroughly, also, a field trip took place to identify and localize the evangelical religious and cultural manifestations inside the SRS, which were later mapped through a GIS to create a thematic map. These results will make possible to characterize such manifestations according to each evangelical church denomination, such actions will provide scientific and methodological knowledge to the IP 29 A/427-1 and to the student's formation in research.

Keywords: Southern Patagonia; religion; christianism; municipal land; XXI century.

\section{INTRODUCCIÓN}

La Geografía Cultural, ha tenido escaso desarrollo dentro de la disciplina geográfica. Actualmente, se realizan investigaciones enmarcadas en la Geografía Cultural renovada. Este es el caso de las religiones, históricamente estudiadas desde la descripción y en sus características más básicas, para hoy estudiar su influencia en la identidad territorial a distintas escalas. Hay una nueva mirada de la Geografía de las Religiones como enfoque emergente vinculado a la renovada Geografía Cultural, que aporta nuevos conceptos y categorías de análisis. (Santarelli y Campos, 2011: 2).

Son escasos los trabajos relacionados a Río Gallegos, ciudad intermedia de la Patagonia Austral Extraandina. Por esto, el tema central de la presente Beca de Iniciación a la Investigación de un Alumno Avanzado en la Licenciatura en Geografía y su finalidad, es el estudio del culto evangélico en la ciudad de Río Gallegos, para la identificación, localización y caracterización en la Segunda Franja Residencial (SFR).

Se plantean dos objetivos, el primero es relevar y analizar bibliografía específica sobre la Geografía Cultural y la Geografía de las Religiones en particular; el segundo es identificar, caracterizar y cartografiar manifestaciones culturales religiosas relacionadas al culto evangélico en la SFR de Río Gallegos. Por otro lado, se trata de una investigación exploratoria, por ser un tema poco estudiado en Río Gallegos y descriptiva, porque se describe y caracteriza a las iglesias evangélicas de la SFR.

La SFR es un área residencial con predominio de este uso del suelo, que surge a partir de la provincialización de Santa Cruz (1958), intercalado con otros usos del suelo, entre ellos el religioso. En referencia al culto evangélico en Río Gallegos, el artículo "Núcleo formativo del campo evangélico: heterogeneidad identitaria en Río Gallegos (Santa Cruz) hacia fines de 1950" de Héctor Mancilla (2009), es la base histórica sobre esta religión. Antecedentes de la Geografía de las Religiones en Río Gallegos, son el trabajo de Alicia P. Cáceres (2011), "Distribución espacial de los edificios religiosos, según áreas de la estructura interna de Río Gallegos" y el de Cristian Ampuero (2011), "La veneración del Nazareno de Caguach en la ciudad de Río Gallegos, Patagonia Austral Argentina".

La hipótesis es: las manifestaciones culturales religiosas relacionadas al culto evangélico, se pueden identificar, localizar y caracterizar en la Segunda Franja Residencial de Río Gallegos, por tanto, es posible estudiar estos fenómenos culturales en el marco de la Geografía de las Religiones. 
Metodológicamente, se recurrió a la lectura de bibliografía específica, se realizó una salida de campo, se trabajó en gabinete y se utilizó el programa Qgis Essen para la confección de los mapas temáticos.

Con esta investigación se espera aportar al conocimiento científico y a la metodología de estudio relacionada a la Geografía Cultural y de las Religiones en relación a la ciudad de Río Gallegos. Asimismo, conocer la dinámica que poseen las denominaciones evangélicas en la SFR.

\section{MARCO DE REFERENCIA}

\subsection{Marco histórico-geográfico}

Respecto a la localización, la ciudad de Río Gallegos, está emplazada en la margen sur del

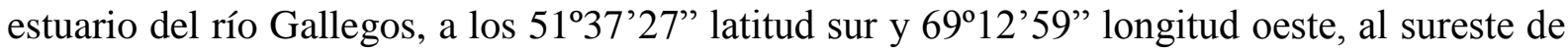
la provincia de Santa Cruz, siendo esta la más austral de la Patagonia Continental Argentina (Figura 1). Según Cáceres (2016), su posición es "austral, extrema, y periférica"; a la vez, se puede mencionar su situación de encrucijada (Cáceres, 1996), dado que dentro de la ciudad coinciden las Rutas Nacionales $\mathrm{N}^{\circ} 3$ y 40, la primera permitiendo la conexión con el resto del país hacia el norte, al sur hacia la provincia de Tierra del Fuego y hacia el sudoeste con la ciudad de Punta Arenas, siendo esta capital de la provincia chilena de Magallanes.

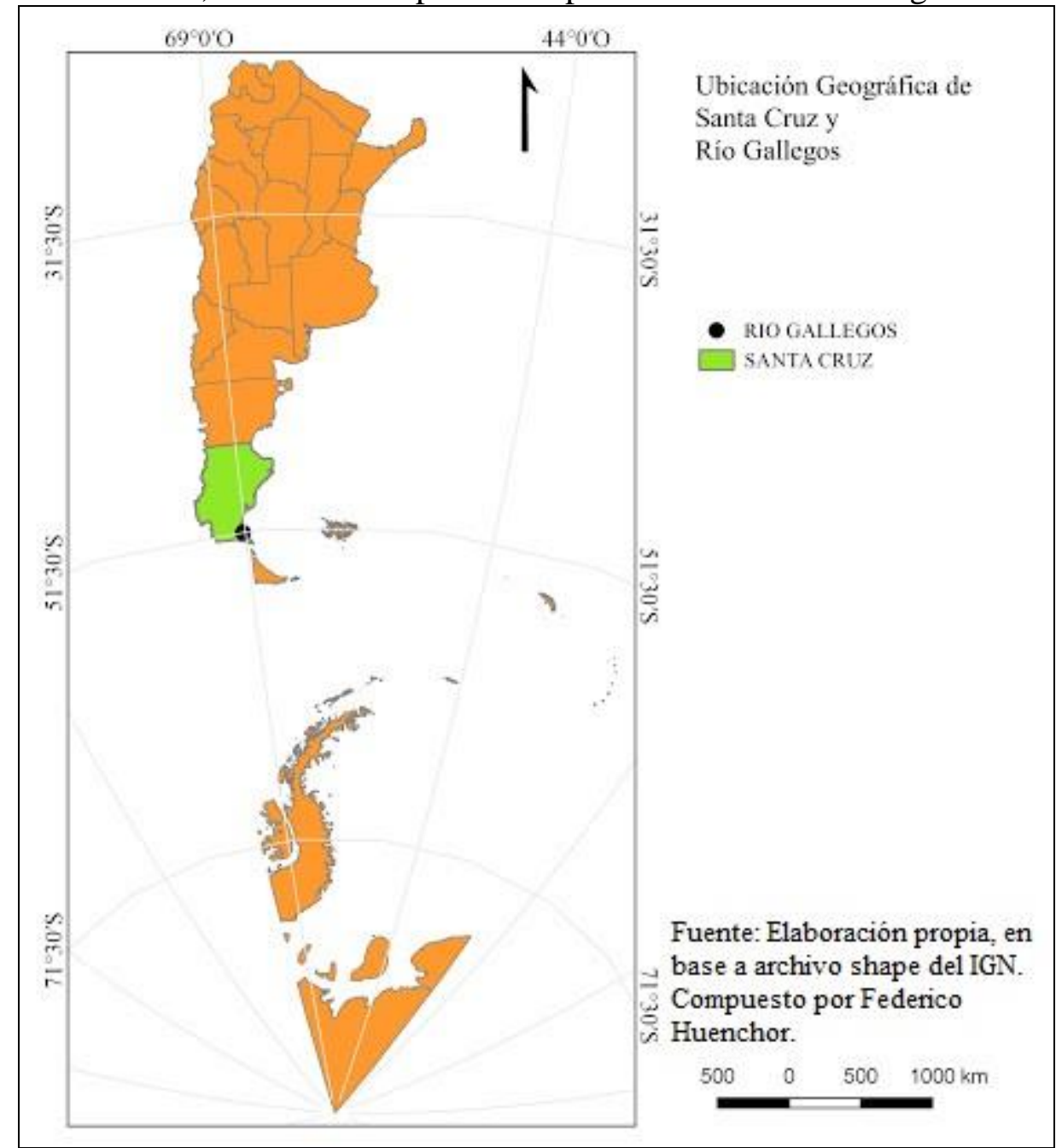

Figura 1. Mapa bicontinental 


\section{Segunda Franja Residencial (SFR)}

Se toma como referencia el trabajo de Cáceres y García del 2004. La Segunda Franja Residencial (SFR) de Río Gallegos se extiende a partir de la terminación del Área Central, y se encuentra enmarcada por la Ruta Nacional 3/40 y las diagonales que empalman con ésta (Figura 2). Morfológicamente, dicha unidad presenta características que la diferencian y nace a partir de la décadas del '60 y '70 del siglo pasado, con el objetivo de recibir a la población proveniente de Chile y del resto de Argentina; se busca el aprovechamiento máximo del suelo, desaparecen los lotes de grandes dimensiones y las calles anchas, se construyen edificios multifamiliares sin ascensores, lo que resulta considerable densidad demográfica y edilicia, aunque estas son menores en comparación con el Área Central.

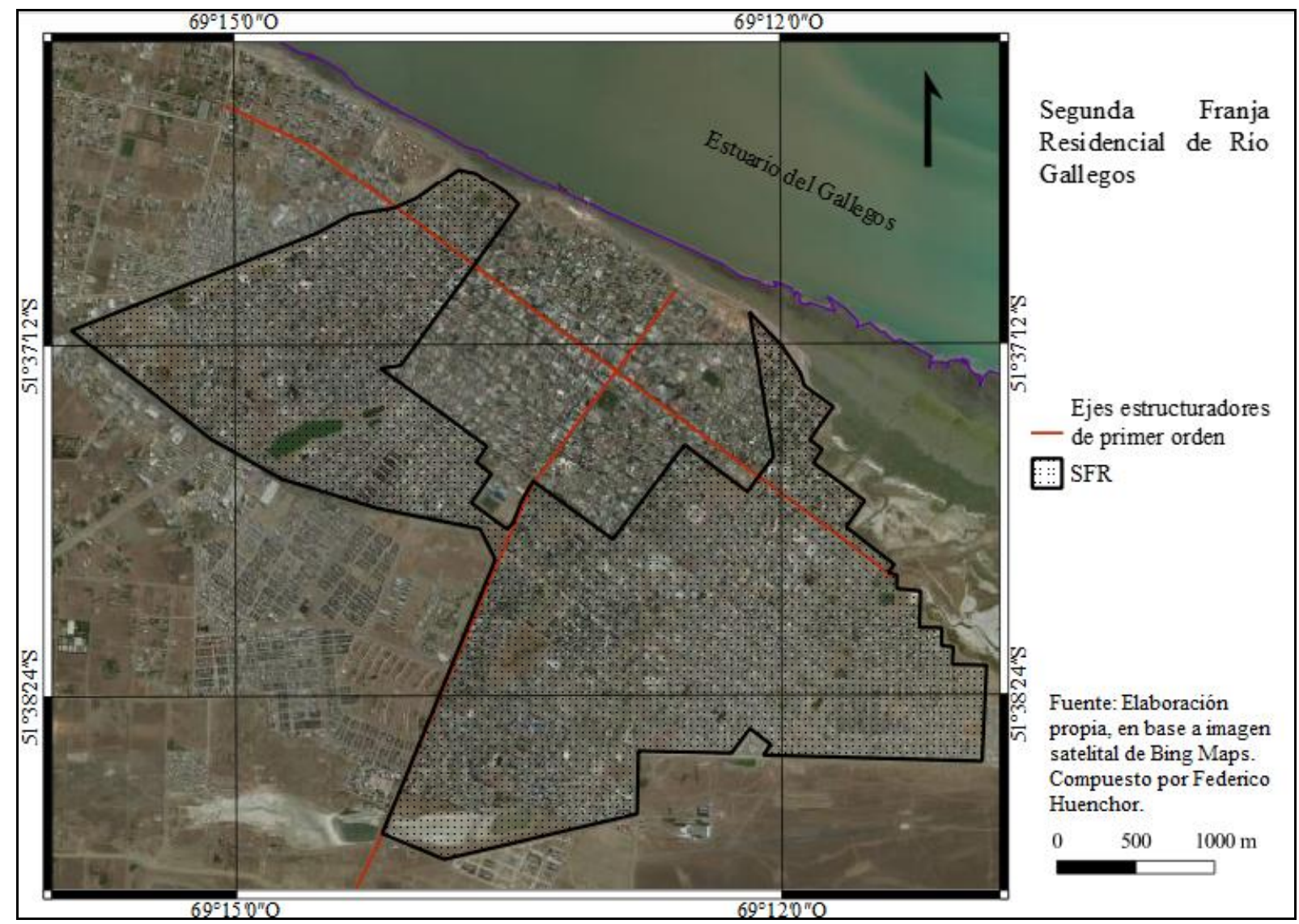

Figura 2. Localización de la SFR en Río Gallegos

Las autoras antes mencionadas, presentan una clasificación de los barrios que componen a la SFR; dicha unidad estará compuesta por tres tipos de barrios: no planificados; planificados por asociaciones civiles y planificados por el estado. Según Cáceres (2019), las calles que funcionan como límites para la SFR son las siguientes: Almirante Brown, Mendoza, Perito Moreno, Hipólito Yrigoyen, Vélez Sarsfield, Provincias Unidas, Rivadavia, Santa Fe, San Martín, Buenos Aires, Salta, Don Bosco, Richieri, Formosa, Sureda, y Emilia Clarke (Figura $3)$.

La SFR aparece en un segundo momento importante de crecimiento de la población, debido no solamente a la importancia de la actividad ganadera y del frigorífico, sino también por el 
asentamiento de la administración de Yacimientos Carboníferos Fiscales (YCF) de los campamentos de Yacimientos Petrolíferos Fiscales (YPF) y de la administración pública" (Cáceres y García; 2004:17).

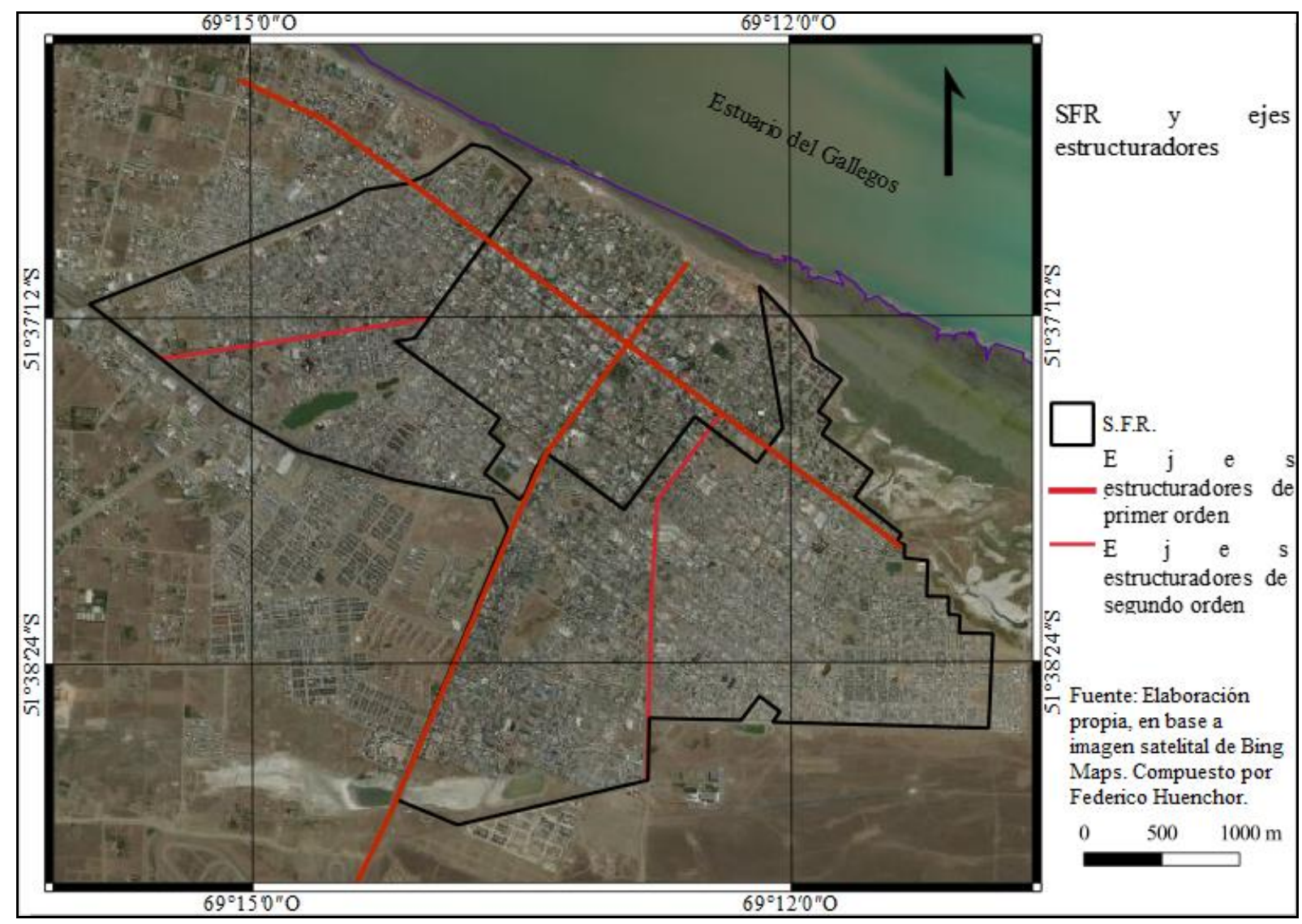

Figura 3. Ejes estructuradores de $1^{\circ}$ y $2^{\circ}$ orden en la SFR

El crecimiento y consolidación de la SFR se dio hasta fines de la primera década del siglo XXI; es la Av. San Martín el eje estructurador de primer orden de la ciudad, que divide en sector occidental y oriental a esta franja. Dentro de cada sector se extienden dos diagonales (Lisandro de la Torre y Santiago del Estero - Gobernador Gregores, respectivamente), que a su vez los dividen en Occidental norte y sur y Oriental norte y sur. Cabe aclarar que en cada sector, a su vez, se identifican diferentes tipologías de barrios (Figura 4).

Conforme a la legislación vigente (Ordenanza N $N^{\circ} 3259$ del 2012) para zonificación en la ciudad de Río Gallegos, quedan establecidas las distintas "categorías de uso" (Preferencial, permisible, no previsto, uso prohibido y uso no conforme), y los "usos" (habitacional, unifamiliar, multifamiliar, comercial, servicio a la comunidad, institucional, esparcimiento, deportivo, entre otros). Esta legislación reconoce a los edificios religiosos como uso "servicios a la comunidad".

Sector Occidental norte: delimitado por la Av. Almirante. Brown (N), calles Mendoza Perito Moreno (E); Av. Ricardo Balbín (O) y Lisandro de la Torre - Autovía 17 de Octubre (S). La mayor superficie del sector está ocupada por barrios construidos por la inmigración chilena (Nuestra Señora del Carmen) "cuya identidad está dada por el estilo arquitectónico de las viviendas con buena adaptación al marco natural" (Cáceres y García; 2004:17). Barrios para trabajadores de la extracción del carbón, en los distintos momentos de la empresa YCF, 
luego privatizada en 1994 y convertida en Yacimientos Carboníferos Río Turbio SA (YCRT SA), re estatizada en 2002 al Estado nacional, con la denominación de YCRT. En 2010 fue inaugurado el último barrio para propietarios relacionados con esa empresa. El resto del sector, ha sido ocupado por viviendas de construcción particular, con diferentes diseños arquitectónicos, durante el siglo XX, con predominio de la unifamiliar.

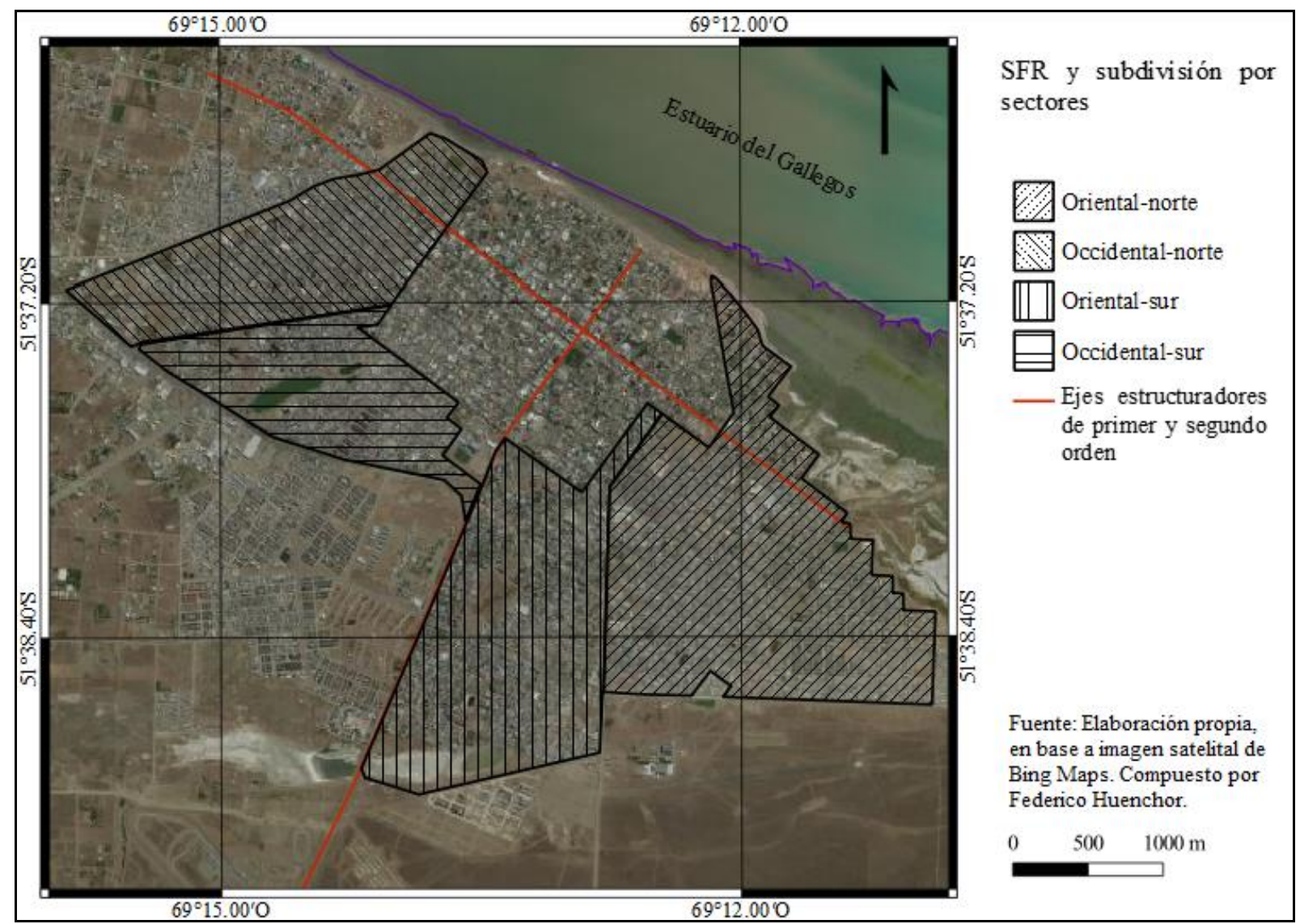

Figura 4. Sectores de la SFR

Sector Occidental sur: delimitado por las calles Lisandro de la Torre, Perito Moreno Hipólito Irigoyen (N), Estrada, Provincias Unidas, Vélez Sarsfield, Rivadavia, Santa Fe, San Martín (E); empalme de Lisandro de la Torre con Autovía 17 de Octubre (O) y Autovía 17 de Octubre (O). Entre las décadas de 1960 y 1970, se construyeron barrios por parte de asociaciones civiles para migrantes argentinos, adosados al eje de expansión. Como ejemplo, los barrios Gregores e YPF sobre Lisandro de la Torre, este último limitando con la autovía 17 de Octubre, ex $\mathrm{RN}^{\circ}$ 3/40. Asimismo, se registran "barrios planificados por el estado de viviendas uni y multifamiliares adosados a los ejes de expansión: Jorge Newbery y Cuatrocientos Departamentos" (Cáceres y García; 2004:17). Ambos barrios, adosados a la Autovía 17 de Octubre. En este sector, se localiza el barrio Fátima con viviendas unifamiliares particulares, que desde la década de 1980, comenzaron a ser compradas por la colectividad gitana, cuyo estilo arquitectónico de casas amplias y de grandes ventanales, combinan con el uso del suelo comercial, rubro venta de automotores. El resto del sector, sigue en proceso de consolidación con viviendas de construcción particular tanto uni como multifamiliares, con diferentes diseños arquitectónicos.

Sector Oriental sur: delimitado por la Av. Pte. Kirchner, calles Salta, Buenos Aires (N), Santiago del Estero, Gobernador Gregores (E); Av. San Martín (O) y Piloto Lero Rivero (S). 
Se localizan barrios de viviendas unifamiliares construidos entre las décadas de 1960 y 1970 por asociaciones civiles para migrantes argentinos, adosados al eje de expansión. Como ejemplo, los barrios APAP, Provincial y Planeamiento sobre avenidas Paradelo, San Martín y Gregores, respectivamente. Además, se localizan "barrios planificados por el Estado de viviendas uni y multifamiliares adosados a los ejes de expansión: "366 Viviendas, 499 Viviendas y Centenario" (Cáceres y García; 2004:17), todos sobre Av. Juan Domingo Perón construidos en la segunda mitad del siglo XX.

Sector Oriental norte: delimitado por las calles Emilia Rodiño de Clark, Carlos Gardel, Gobernador Mayer, Arsenio Tur, Quinquela Martín, Lavaque, Pedro de Gamboa, Isidro Guadarrama, Marcelino Álvarez, Capitán Giachino, Don Bosco, Prefectura Naval, Alvear, Servicio Penitenciario Federal, Belgrano, Cerro Dos Hermanas, Ramón Cajal (N), Escribano Don Pedro Renna (E), Av. Sureda, Formosa, Av. Kirchner, Santiago del Estero, Av. Gobernador Gregores (O) Crucero General Belgrano (S). La ocupación del sector es a partir de la llegada de inmigrantes chilenos quienes construyeron el barrio Belgrano "cuya identidad está dada por el estilo arquitectónico de las viviendas con buena adaptación al marco natural" (Cáceres y García; 2004:17). El resto del sector, continúa en proceso de consolidación, primero con la construcción de numerosos barrios uni y multifamiliares por parte del Estado provincial. Luego con la entrega de lotes para el uso residencial de construcción particular, con diferentes diseños arquitectónicos, durante el siglo XX, con predominio de la unifamiliar.

\section{El culto evangélico en la provincia de Santa Cruz}

Con relación al culto evangélico en Santa Cruz y particularmente en Río Gallegos, se consultó la obra de Mancilla (2009), este autor hace un recorrido histórico de la conformación del mismo.

Los primeros protestantes en Santa Cruz fueron anglicanos y tuvieron gran visibilidad social en las primeras etapas de la ocupación del territorio, la que disminuyó entre las décadas de 1920 y 1940. La comunidad inglesa representó un 30\% del flujo de inmigrantes europeos y se desarrolló institucionalmente (Colegio Británico, British Club, otros), pero no se estableció una iglesia permanente. Las necesidades religiosas (casamientos, bautizos, funerales, etc.) de las comunidades de Río Gallegos y San Julián eran cubiertas por la misión de Saint James en Punta Arenas (Chile), o por servicios religiosos itinerantes.

En 1940 había baja demanda de bienes religiosos, por la escasez de miembros activos y la paulatina conversión de la comunidad al catolicismo. En 1943, el gobierno de facto perjudicó el contexto nacional en relación a la libertad de culto; este, se identificaba con el mito de la nación católica. Se adoptó una política de control y seguimiento a causa de una creciente preocupación por la expansión de "propaganda protestante" en el país. En este sentido, en 1945 en Santa Cruz circuló una nota dirigid al gobernador del Territorio, las comisarías y subcomisarías, en la que se advertía sobre "el peligro de la propaganda religiosa, especialmente la metodista". En la circular, se instaba a la vigilancia de estas manifestaciones ya que "la adaptación de costumbres foráneas por medio del culto religioso, no era otra cosa que propaganda extranjera de infiltración”. Para 1947, los inmigrantes que ocupaban el primer lugar eran de países limítrofes, superando a los europeos, siendo los del extremo sur de Chile el mayor componente. Este cambio de grupo migratorio comenzó a modificar la estructura religiosa del entonces territorio. 
Ya en el año 1950, las restricciones que afectaban a los protestantes, como la prohibición de emitir programas radiales, negarles permisos para organizar encuentros, entre otros, fueron disminuyendo por el enfrentamiento de Perón con la Iglesia Católica; esto posibilitó la apertura hacia el reconocimiento de las minorías religiosas en comparación con la década anterior. Este contexto dio comienzo al "núcleo formativo del campo evangélico", a partir de tres modos y etapas de evangelización: por el aporte migratorio, por la interacción de los grupos evangélicos locales y por acciones esporádicas de misiones evangelizadoras externas. Asimismo, en este mismo año, se registraron las primeras actividades de los grupos evangélicos de manera organizada. Hasta ese momento, las prácticas religiosas protestantes estaban restringidas a "cultos privados". Estos grupos establecieron vínculos sociales entre sí y comenzaron a interactuar en el ámbito urbano. Las transmisiones radiales de los culto dominical fueron la herramienta que tenían las comunidades para estar comunicadas a nivel nacional e internacional.

Entre 1953 y 1955, se formó un grupo estable a nivel local, a partir del reconocimiento a su identidad religiosa y cultural, aunque fueron rechazados y discriminados por la sociedad. La movilidad y el crecimiento en cantidad de miembros, se intensificó por la inmigración que llegaba, sobre todo del sur de Chile, los cuales no se desprendian de su identidad evangélica heterogénea (principalmente pentecostales y bautistas, en menor medida metodistas). En 1958 se gestan espacios públicos para la socialización religiosa.

Entre 1958 y 1960, en Santa Cruz se produjeron cambios acelerados como consecuencia de la provincialización del territorio. Río Gallegos comenzó a transformarse en un centro administrativo, comercial y financiero, con crecimiento poblacional y ejecución de obras de infraestructura.

Hacia finales de la década de 1950, con llegada del pastor canadiense Walter de Smet, se creó la primera iglesia permanente, la "Evangelical Union of South America (Trust Association Limited-Union Evangélica de Sud America). Durante la década de 1960 esta pasará a llamarse Iglesia Evangélica de Río Gallegos. En la actualidad, se la conoce como "Jesús es el camino" e integra el conjunto de iglesias tradicionales del evangelismo nucleadas en la Unión Evangélica Argentina (U.E.A). En este periodo, la Municipalidad comenzó a regular las actividades externas de evangelización realizadas por grupos no católicos. Estas tenían que contar con autorización previa, dado que eran consideradas actividades callejeras de publicidad propias de las asociaciones comerciales.

En la década de 1960, se forma otro movimiento nacional evangélico importante en Mar del Plata por el evangelista estadounidense Tommy Hicks y se inicia un movimiento de renovación espiritual que produjo una proliferación y dispersión de pastores independientes que buscaron expandir el evangelismo a otras regiones del país, incluido el sur argentino y, por supuesto, Río Gallegos.

En la segunda mitad del siglo XX, se dan dos eventos importantes: primero, la celebración de la $1^{\text {a }}$ Convención constitutiva del Movimiento Cristiano y Misionero de la Patagonia, que contó con representantes de Santa Cruz (Río Gallegos, Río Turbio, San Julián y Puerto Deseado), Chubut (Comodoro Rivadavia), Tierra del Fuego (Río Grande y Ushuaia) y de la República de Chile (Puerto Natales) y; el segundo, el inicio de la Iglesia Evangélica Bautista de Río Gallegos, que integra el grupo de primeras iglesias en la ciudad. 
Finalmente, en este proceso de formación convergen grupos protestantes diversos que se constituyeron como una comunidad evangélica inicial con una identidad religiosa caracterizada por la necesidad de socialización religiosa y cohesión social, a nivel local. El primer protestantismo fue representado por los anglicanos, el segundo por metodistas y adventistas y el tercero, por movimientos pentecostales.

Hasta el momento, Mancilla (2009) es el único autor encontrado en el relevamiento de bibliografía específica referida al culto evangélico, que trata este tema en relación con la provincia de Santa Cruz y Río Gallegos.

\subsection{Marco teórico-conceptual}

\subsubsection{Geografía Cultural}

Al relevar y analizar la bibliografía específica, se observa que desde fines del siglo XX dentro de la Geografía Cultural quien se descata es el geógrafo francés Paul Claval (también se puede mencionar a Lopez-Levi, Berque, Bonnemaison, entre otros), y con respecto a la Geografía de las Religiones, principalmente la obra de Santarelli y Campos (pero también a Cáceres, Carballo, e Hidalgo).

Según Paul Claval (2000), la Geografía Cultural es la rama de la Geografía Humana, que se enfoca en los patrones e interacciones de la cultura (material e inmaterial), en relación con el ambiente y la organización humana del espacio. Autores alemanes, norteamericanos y franceses coinciden en su concepción de la cultura. Vidal de la Blache y Ratzel coinciden en que es "aquello que se interpone entre el hombre y el medio, y humaniza los paisajes. Se puede entender como una estructura generalmente estable de conductas que es importante describir y explicar (Claval, 2000:35).

Por otra parte, López Levi menciona que "analizar el territorio, su estructura, su conformación y dinámica desde los estudios culturales permite recorrer recovecos que van más allá de lo tangible, de lo concreto, de lo material, para dar cuenta de la forma en que los actores sociales y sus prácticas van conformando el paisaje, construyendo su imagen, utilizando sus espacios, habitándolos y dándoles un sentido" (López Levi, 2010:1).

Dentro de la Geografía Cultural renovada, Claval (1999) en su obra "Los fundamentos actuales de la Geografía Cultural", menciona que la cultura es el resultado de un proceso inacabado de construcción de identidades llevado a cabo por las personas. En este proceso se establecen categorías con las que individuos y sociedades analizan la realidad partiendo de una escala local. En una época en que la cultura se aborda en términos de comunicación, el paisaje retiene la atención porque sirve de soporte a las representaciones y es huella y matriz de la cultura. El mismo autor menciona que el estudio de la cultura ha sido renovado por el progreso de la linguiística y de la teoría de la comunicación. La cultura está formada por informaciones, concernientes al medio natural en que viven las personas, la manera de obtener de él alimentos, energías y materias primas, por formas de construir útiles y de emplearlos para crear medios artificiales; también, se refieren a la sociedad, a la naturaleza de los vínculos que unen a sus miembros y a las reglas que deben ser respetadas en las relaciones que se establecen, que circulan entre los individuos y que les permiten actuar. Estas informaciones se transmiten por observación e imitación, por la palabra o por la escritura; componen las culturas, no cesan de transitar de individuo a individuo: pasan de una 
generación a otra, de forma que la sociedad permanece mientras sus mayores desaparecen y son reemplazados por personas jóvenes.

La cultura da sentido a la existencia de individuos y de los grupos en que se insertan; estos no permanecen pasivos ante ella. El universo en que se mueven los individuos está estructurado por representaciones que resultan de su actividad y de la de quienes les rodean. Las categorías que la humanidad utiliza para describir el mundo, son construidas por la cultura. Es necesario estudiar cómo se dividen y ver en qué marco están, para comprender cómo las culturas nacen, se reproducen y se transforman.

Las personas se desarrollan sin dificultades en el marco del conocimiento científico o se dedican preferentemente a la vida religiosa. Cuando las gentes participan de las mismas creencias, comparten los mismos valores y asignan a su existencia objetivos parecidos, nada se opone a que se comuniquen libremente entre ellas. Estas ideas se aferran al espacio: reposan sobre recuerdos compartidos, lugares visitados por todos, monumentos que reavivan la memoria de los grandes momentos del pasado, símbolos recordados por todas partes a través de la piedra de las esculturas o de las inscripciones. Bonnemaison, 1986; Keith y Pile, 1993 citado por Claval (1999), definen que la territorialidad se ha convertido en uno de los componentes más importantes de las nuevas orientaciones del mundo social y político.

La cultura se manifiesta en primer lugar, a escala local, en esta se producen intercambios y formas para que la comunicación sea posible, aunque no todo es transmitido. La escala de análisis se transforma para aprehender los procesos culturales verdaderamente significativos, los geógrafos se basan en la experiencia de las personas, en sus contactos, sus formas de hablar. Las acciones cambian y los objetos colectivos se construyen a partir de las interacciones. Las investigaciones se centran en escalas locales en el espacio geográfico urbano y en el rural, más que en escalas globales. Estos estudios aportan ideas que varían constantemente.

Los geógrafos se interesan por las cuestiones culturales ya que es de relevancia el lugar del arte, de las relaciones de la sociedad con la naturaleza, el significado de los paisajes o la percepción de los grupos sociales sobre el espacio. Al ser abordada la cultura en términos de comunicación, el paisaje retiene la atención porque sirve de soporte a las representaciones.

Augustin Berque (1984), citado por Claval (1999) hace referencia al paisaje como matriz e impronta de la cultura. Las instalaciones y las formas que lo estructuran contribuyen a transmitir usos y significados de una generación a otra; impronta, porque cada grupo contribuye a modificar el espacio que utiliza y a grabar las marcas de su actividad en él - esto es lo que estudiaba la geografía de principios de siglo - y los símbolos de su identidad. Las personas inscriben en los monumentos y en las inscripciones, el orden de significaciones que les atañen. El paisaje es, entre las creaciones de la cultura, la que retiene la mayor atención, pues se ha lanzado sobre él una nueva mirada. Todas las culturas son el producto de un trabajo de construcción y disponen de savoir-faire relativos al espacio, la naturaleza, la sociedad, los medios y las maneras de explotarlos. Resulta interesante comparar estos savoirfaire, analizar sus bases y sus modos de elaboración e inventariar las categorías sobre las que reposan. También conviene detenerse en la manera cómo estos conocimientos son utilizados, reinterpretados, respetados (o transgredidos), en su parte normativa, por aquéllos que los ponen en marcha. 
Los cambios que se produjeron en la geografía desde fines de la década de 1950 han llevado a una transformación profunda de las actitudes. Durante la década de 1960, su evolución aún se inscribía en un clima positivista. Contra éste se inscribieron los movimientos fenomenológicos y radicales que se desarrollaron en la década de 1970. Actualmente, las investigaciones se orientan hacia el mundo sometido al proceso de desarrollo. La rapidez, el costo de viajes y las telecomunicaciones facilitan la difusión de las técnicas y de los comportamientos.

La geografía cultural francesa está mejor estructurada y saca mejor provecho de las corrientes más variadas; se ha interesado por la forma cómo las realidades espaciales, el territorio, la región y el paisaje estaban construidas. Por otra parte, la geografía cultural anglosajona acentúa la reinterpretación al que dan lugar las realidades geográficas y subrayan su inestabilidad, se interesa por los lugares y los paisajes, pero su atención va sobre todo a la construcción de categorías sociales que definen el sexo, la clase, el extranjero.

En este contexto, es de importancia estudiar el espacio geográfico desde la óptica de la religión, siendo esta uno de los componentes de la cultura.

\subsubsection{Geografía de las Religiones}

Santarelli y Campos en "Geografía de las Religiones, espacios locales y subjetividad. Una nueva mirada en la enseñanza universitaria", del año 2011 realizan un recorrido por los aspectos más relevantes de esta rama. Las autoras exponen que "el hombre, desde sus orígenes, en una búsqueda permanente de respuestas a necesidades espirituales adhirió a creencias y religiones; así, las instituciones religiosas siempre constituyeron centros de poder y tuvieron un papel preponderante en la construcción y organización de espacialidades con fuertes manifestaciones en el paisaje" (Santarelli y Campos, 2011:3).

La Geografía relacionada a las Religiones, surge como un enfoque emergente dentro de la renovada Geografía Cultural, aportando nuevos conceptos y categorías de análisis para comprender las diversas relaciones entre las sociedades y el espacio local vinculadas a prácticas basadas en el ejercicio de la fe (Santarelli y Campos, 2011:3). Conocer la esencia de las religiones, conlleva comprender la lógica de las acciones guiadas por la fe y de los escenarios de interacción. Las distintas religiones construyen espacios sagrados diferenciados dentro de una misma religión, por lo que será posible diferenciar distintos modos de ocupar y apropiarse de los territorios de acuerdo al carisma de la congregación que los lleve a cabo.

Según Cáceres (2012), el rol de las instituciones religiosas en la organización del territorio es claramente visible en el paisaje, dado que las distintas denominaciones religiosas construyen espacios sagrados diferenciados en su modo de ocupar y apropiarse de ellos.

Hidalgo (2012), citando a Dando (2009) y Warf y Vincent (2007) mencionan que el estudio geográfico de las religiones, estuvieron presentes desde los inicios de la ciencia, por su importancia en la vida individual y social, por las relaciones de poder imperantes al interior de las formaciones sociales y de la identidad de las colectividades. Los estudios geográficos revelan en qué medida la localización de los templos y/o edificaciones religiosas dan cuenta de los objetivos que cada congregación persigue en materia de evangelización, considerando que cada grupo religioso orienta su oferta a la captación de posibles interesados al interior de la ciudad (Hidalgo et al; 2012:48). 
En cuanto a consideraciones teórico metodológicas relacionadas a la Geografía Cultural y a la de las Religiones, se adoptan conceptos, como el de espacio sagrado definido por Zeny Rosendahl (2002, citado por Santarelli y Campos, 2011) como un campo de fuerzas y de valores que eleva al hombre religioso por encima de sí mismo; en cuanto expresión de lo sagrado, posibilita al hombre a entrar en contacto con una realidad trascendente llamada dioses, en las religiones politeístas y Dios en las monoteístas. (Santarelli y Campos, 2011:3) Por otra parte, se integran conceptos a la Geografía de la Religiones, tales como geosímbolo religioso, definido como un lugar, un itinerario, un objeto, que por el significado que las personas le otorgan toma una dimensión simbólica desde lo religioso para un determinado grupo. Por otro lado, en relación a los lugares, la subjetividad espacial se refiere a los significados otorgados al espacio por las prácticas que brindan información espacial.

Por su parte, Carballo (2008) explica que actualmente, en las grandes ciudades conviven las manifestaciones culturales de religiones tradicionales, con nuevos templos, ofrendas en los espacios públicos a "santos" populares, santerías en pleno centros comerciales, consultorios de tarot, rituales o encuentros de grupos religiosos de carácter masivo -ya sea en puntos neurálgicos de las ciudades como avenidas o estadios- que adquieren identidad pública y popular (Carballo, 2008:32). En la dimensión de las creencias, estas transformaciones, se asocian con la ruptura de la homogeneidad de los campos de las religiones institucionales (católicos y protestantes históricos), o con los nuevos movimientos religiosos algunos para élites o para sectores populares, según corresponda. (Carballo, 2008:34)

En relación a la multiplicidad de religiones y de denominaciones o divisiones dentro de estas, no es sencillo catalogar la presencia territorial en las ciudades de cada una. La ciudad expresa espacialmente la complejidad de las creencias, y a medida que se adentra en algún campo o sub-campo, los factores, procesos, estructuras y símbolos, permiten ver a una ciudad distinta, a una geografía de rituales y prácticas que le dan identidad y la materializan en un particular paisaje social. Elementos para el bienestar espiritual aparecen y son ofrecidos en medios gráficos, la televisión o en la calle, según la demanda del consumidor. Estos se convierten en señales indiscutibles para el estudio de la espacialidad religiosa. Actualmente, resulta dificil entender los rasgos y prácticas religiosas presentes en la sociedad y espacio desregularizado. La ruptura del monopolio católico y la aparición de otras necesidades de expresión espiritual dejan de lado al mapa homogéneo, el que resulta insuficiente para comprender la dinámica espacial del campo religioso en Argentina. (Carballo, 2008:38)

Finalmente, en términos territoriales, Carbonelli y Mosqueira (2008) en relación a Latinoamérica, dicen que los cultos cristianos no-católicos tienen un largo recorrido desde la "tolerancia" de las prácticas privadas protestantes para grupos étnicos extranjeros, en la época tardo-colonial, hasta los actos masivos de predicadores transnacionales que se consolidan a partir de la década de 1990. También las sociedades históricamente marcadas por la presencia monopólica del catolicismo, han abierto su perspectiva aceptando la presencia paulatina, pero creciente, de personas, grupos e instituciones que disputan al catolicismo su lugar hegemónico en el espacio religioso y social. (Carbonelli y Mosqueira, 2008:65-66)

Dejando de lado la Geografía de las Religiones y considerando el área de estudio, se debe mencionar que en esta investigación intervino la Geografía Urbana, ya que el trabajo se realizó en el ámbito de una ciudad. Los Sistemas Urbanos son estudiados a través de dos escalas: la interurbana y la intraurbana que comprende tres componentes formales: el tipo de plano, el uso del suelo y la construcción. La combinación de estos tres a través del tiempo, determinan la morfología urbana o paisaje urbano. 
En en esta investigación se profundizó en el componente formal Uso del Suelo, entendido como "la función o utilidad que tiene una porción del espacio según sean las necesidades de la sociedad” (Glosario de términos geográficos, 2005,29).

\subsubsection{Denominaciones presentes en Río Gallegos}

Se caracterizó a las Iglesias Cristianas Evangélicas presentes en Río Gallegos con o sin denominación/es según lo expuesto por varios autores, sitios web, webs oficiales, blogs, wikis, diccionarios, entre otros espacios dedicados a la religión objeto de estudio (Norambuena, 2019). En primer lugar, se explican las Iglesias Cristianas Evangélicas con denominación por orden alfabético: Adventista, Apostólica, Bautista, Metodista o Metodismo, Misionera, Pentecostal o Pentecostalismo, Unión de las Asambleas de Dios/ Asambleas de Dios. En segundo lugar, las Iglesias Cristianas Evangélicas sin denominación.

Adventista: más de diecisiete millones de miembros en el mundo, es una iglesia cristiana protestante organizada en 1863 en Estados Unidos. Originada por Guillermo Miller, quien hizo hincapié en la necesidad de predicar sobre el pronto regreso de Jesucristo a este mundo. En Sudamérica, en ocho países con más de dos millones de miembros. Idea central: Vida de consagración a Dios en el aspecto físico, psicológico, emocional y espiritual. Estilo de vida: remedios naturales: agua, descanso, ejercicio físico, luz solar, aire puro, nutrición equilibrada, temperancia y esperanza en Dios. Descanso el día sábado. "Dios obra en todas las áreas de la vida y seguridad de que Cristo volverá pronto para recompensar a quienes confiaron en Él. Biblia: segura y única regla de fe y esperanza, escrita y transmitida por inspiración divina. Sus autores hablaron y escribieron impulsados por el Espíritu Santo. Son la norma del carácter, el criterio para evaluar la experiencia. Hay un solo Dios: Padre, Hijo y Espíritu Santo, unidad de tres personas coeternas. Dios es inmortal, todopoderoso, omnisapiente, superior a todos y omnipresente, infinito y escapa a la comprensión humana. Se lo conoce por medio de su autorrevelación. Dios, que es amor, es digno, para siempre, de reverencia, adoración y servicio por parte de toda la creación". En Argentina 18 de agosto de 1894, Frank H. Westphal llegó con su familia para trabajar en el territorio de la división Sudamericana; el 9 de septiembre de 1894 organizó la primera Iglesia Adventista del Séptimo Día, en Crespo (Entre Ríos). A partir de ese momento, el mensaje adventista se diseminó progresivamente. Actualmente, presencia en todas las provincias de Argentina.

Apostólica: surge entre el 30 y el 100 d.C. Desde Pentecostés a la muerte del apóstol Juan. Emerge en Pentecostés con un tema central a comunicar, la persona de Jesucristo (su ministerio, muerte, resurrección, ascensión, y regreso). Discípulos comisionados a ir y ser testigos de la persona de Jesús desde Jerusalén hasta lo último de la tierra. Cambio de perspectiva por la obra del Señor en la vida de los primeros cristianos. Iglesia compuesta por judíos y liderada por los apóstoles (también judíos). Emerge en ambiente cristo-céntrico, expectante de la venida del Señor. Enseñanza del Antiguo Testamento, sobre Jesucristo y líderes emergentes. Iglesia en Jerusalén, desafío de mirar hacia el exterior para llevar a otros el mensaje de salvación. Propagación y difusión del evangelio a través de "estímulos" para su expansión. Estímulos: persecución y dispersión de judíos por las autoridades romanas. Concilio de Antioquía, 50 d.C. se comienza a llamar cristianos a los seguidores de Cristo, sin hacer distinción entre judíos y gentiles (no judíos). Características: fervor y gozo en la iglesia primitiva. Mundo terrenal sin mayor importancia para quienes creyeron en Jesús como el Mesías prometido. Idea central: "si la verdadera vida ahora está en Jesús, mi vida debe girar 
en torno a Él y el cumplimiento de su voluntad, por lo que, todo lo que este mundo ofrece es y debe ser secundario". En Argentina: 1900 en adelante, proveniente de Chile, como pequeñas congregaciones que fueron creciendo y se instalaron en las principales ciudades de Argentina, varias en la Patagonia. Labor centrada en el trabajo con hombres, mujeres y niños. Actividades centradas en estudios bíblicos, programas de canto, entre otras. Actualmente se han incorporado trabajos de evangelismo, escuelas bíblicas, entre otras.

Bautista: surge en Holanda en 1608-1609, John Smyth, funda la primera iglesia con ese nombre. Smyth (anglicano), había fundado una iglesia «separatista» en Gainsborough. Su discípulo Thomas Helwys fundó una iglesia bautista en Londres y publicó (por primera vez en Inglaterra) un alegato defendiendo la libertad absoluta de religión (1612). La iglesia de Smyth es la primera en una larga línea de iglesias bautistas. Éste recibió la influencia de los anabautistas holandeses (menonitas) y rechazó el bautismo de infantes. A mediados del siglo XVII, iniciaron la práctica de bautizar únicamente por inmersión. Se dividieron en generales (Arminianismo) y particulares (Calvinismo). Unión de bautistas generales y particulares en el siglo XIX. Sostienen las doctrinas básicas de los evangélicos, con los que se identifican e instan a la experiencia personal de conversión. Los bautistas se organizan en convenciones, uniones y asociaciones, de ellas la mayor es la Convención Bautista del Sur de Estados Unidos; en los siglos XIX y XX, se convirtieron en la más numerosa denominación protestante en el país y son el principal movimiento religioso en el sur. Son numerosos en Rusia, Ucrania, Inglaterra, India, Canadá, Brasil y otros países. Se agrupan en la Alianza Bautista Mundial, con sede en Londres. Además hay un número apreciable de iglesias independientes que se identifican como bautistas o sustentan una teología compatible. Entre las divisiones que se encuentran dentro de la denominación Bautista, existen los Bautistas Libres, los Particulares, los Primitivos, los Reformados, los Regulares, los Shouter, los Unidos, entre otros. Ideas centrales: bautismo por inmersión y para creyentes; pacto de la Gracia; vida espiritual interior; seguridad de la Salvación; autonomía entre la Iglesia y el Estado; supremacía de la Biblia sobre la tradición; supremacía de la Fe sobre las obras; supremacía del pueblo sobre el clero; señorío de Jesucristo; libertad religiosa y libertad de conciencia. En Argentina: el primer bautista registrado de la historia es Diego Thompson, quien llegó a Buenos Aires el 6 de octubre de 1818; este recibió apoyo del presidente Bernardino Rivadavia y de su ministro Martín Rodríguez. En 1821 funcionaban 16 escuelas en la ciudad y el campo. El 19 de noviembre de 1820 se realizó el primer culto bautista registrado en el país. Al salir de Argentina rumbo a Chile y luego al Perú, en contacto con el Gral. José de San Martín, el Cabildo de la ciudad de Buenos Aires le concedió a Thompson la ciudadanía honoraria reconociéndolo como un ciudadano ilustre. En 1865 un grupo de bautistas, congregacionales y metodistas que emigraron de Gales se radicaron en el valle del Río Chubut. Su pastor fue Roberto Williams, primer bautista que dirigió una iglesia de su propia fe en territorio argentino y en la Patagonia. En la década de 1880 varios misioneros bautistas llegaron al país. Pablo Bessón (suizo francés) llegó en 1881 como inmigrante a Esperanza (Santa Fe). En 1882 se trasladó a Buenos Aires y organizó la primera iglesia Bautista, actual Iglesia del Centro. Defendió las libertades públicas que la Constitución Nacional consagraba pero que las costumbres y tradiciones religiosas de aquella época negaban. Realizó un casamiento "civil" cuando todavía no existía el Registro Civil, escribió en los principales diarios, tradujo el Nuevo Testamento. En 1903 desembarcó en Argentina, Sidney Sowell (norteamericano), quien organizó la iglesia de Constitución, luego las de Once, Caballito y Chacarita. El $1^{\circ}$ de enero de 1909 se organizó la Convención Evangélica Bautista Argentina. Desde sus inicios, los bautistas argentinos comenzaron obras en países limítrofes y otros de Sudamérica durante todo el siglo XX, lo mismo que en todas las provincias argentinas. En el mismo siglo, los bautistas editaron folletos para evangelizar, impulsaron 
periódicos; en cuanto a la educación, entrenaron maestros, fundaron escuelas, jardines de infantes; en relación a la preparación educacional cristiana, fundaron seminarios bíblicos; atendiendo a las acciones sociales, crearon hogares de niños, entre muchas otras acciones. Además respaldó la creación de la Alianza Cristiana de Iglesias Evangélicas de la República Argentina (ACIERA) y es miembro fundador de la Confraternidad Evangélica Latinoamericana (CONELA).

Metodista o Metodismo: perteneciente al "protestantismo histórico". Europa, siglos XII al XVIII. Proceso de transición del feudalismo al capitalismo. Sacerdocio universal de los fieles, justificación gratuita sólo por la fe y autoridad de la Escritura fuera de toda tradición (pilares teológicos del luteranismo, modificaron la geografía política y religiosa de la Europa medieval). Siglo XVI, multiplicación de iglesias protestantes inspiradas en las reformas de Lutero y Calvino. Siglo XVIII, "avivamiento" religioso en Alemania, alcanzó las clases dominantes luteranas con una ética de la renunciación. Inglaterra, Iglesia Anglicana, movimiento de "avivamiento" y piedad inspirado por Juan y Carlos Wesley. - Resaltan la experiencia religiosa individual y sentimental, la ascesis, la importancia acordada al laicado así como su participación en las reformas del momento (liberación de los esclavos y actividades filantrópicas). Metodismo, movimiento renovador dentro del anglicanismo, pero sin romper lazos institucionales con la iglesia madre. EEUU: Fines siglo XVIII y principios del XIX, Iglesia Metodista Episcopal, rompiendo definitivamente lazos institucionales con la Iglesia Anglicana. Características: Creencias: Dios Padre, Creador del mundo, dador y sustentador de la vida. Jesucristo, verdadero hombre e hijo de Dios (base y centro de la fe). Espíritu Santo como presencia de Dios obrando en la iglesia. Biblia, palabra de Dios. Misión: llamamiento de Dios Padre, Hijo y Espíritu Santo a: proclamación del Evangelio y el testimonio de Jesús; crecimiento integral en el Espíritu; renovación de comunidades que celebren la vida en Jesús; el servicio solidario. Visión: ser una Iglesia Cristiana comprometida con su tiempo y su historia, fiel al Señor Jesucristo, amorosa e inclusiva. En Argentina: 1836, la Iglesia Metodista Episcopal llega a Buenos Aires y establece trabajo misionero entre ciudadanos norteamericanos. 1867, primera predicación en castellano. Expansión territorial. Establecimiento en Buenos Aires, Rosario y Montevideo (Uruguay). 1874, Buenos Aires, inauguración del primer templo. Fines siglo XIX, comienzos del XX, obra en el ámbito educativo, acompañó iniciativas de gobiernos liberales de la época (obra de Sarmiento). Primeras maestras traídas por Sarmiento fueron en su mayoría metodistas. Metodismo, participación en lucha por leyes laicas en 1880, ley de matrimonio civil, de divorcio vincular, de educación laica, creación del Registro civil y prosecución de la separación total entre la Iglesia y el Estado. En 1969, creación de Iglesia Evangélica Metodista Argentina (IEMA).

Misionera: primeros apóstoles realizaron viajes misioneros para predicar el evangelio. Concepto de «misión», históricamente (comienzo siglo XIX) había sido el objetivo de las Iglesias evangélicas en Latinoamérica. Objetivo misional, cinco hitos en la historia del protestantismo en América Latina: 1. la primera evangelización (1492-1550); 2. la cristiandad colonial (1550-1808); 3. la crisis de la cristiandad colonial y romanización del catolicismo latinoamericano (1808-1950); 4. de la iglesia «misionera» a la evangelización liberadora (1954-1972); 5. la nueva evangelización: de Puebla a Santo Domingo (1973-1992). Características: iglesias de trasplante y apéndices religiosos de culturas europeas. Han ignorado la problemática socio-política latinoamericana, tienen un enfoque individualista, cristológico, soteriológico, en clave básicamente subjetiva, con énfasis en la santificación, con un interés social genuino que se expresa en la caridad y la ayuda mutua pero que carece de perspectiva estructural y política. Defensa de la fe y la afirmación del valor de la Biblia. En Argentina: Protestantismo «misional» contiene originariamente a las Iglesias Metodista 
Episcopal, Bautista, de los Hermanos Libres, Ejército de Salvación, Adventistas del Séptimo Día, Alianza Cristiana y Misionera, Discipulos de Cristo, Luterana Unida, Menonita, Luterana Argentina, Nazarena y Congregacional. Casi todas de origen europeo, llegaron a Argentina entre 1881 y 1924 . Misioneros traían el Evangelio como luz a un continente oscurecido por la fe católica. Orientaban sus metas a la expansión evangelista, no se regían por criterios de nacionalidad. Algunas de las misiones más antiguas $-\mathrm{o}$ sectores de ellas-formaron parte de la tendencia liberacionista (Metodistas, Discípulos de Cristo y Luterana Unida). '90 (siglo XX), se genera la Alianza Cristiana de Iglesias Evangélicas de la República Argentina (ACIERA). Finales siglo XX, iglesias demográficamente más dinámicas del protestantismo misional: Bautista y Hermanos Libres.

Pentecostal o Pentecostalismo: Surge al interior del protestantismo norteamericano. Principios siglo XX. América Latina, década de 1960. Iglesias históricas, reivindicación de la experiencia pentecostal: manifestación del Espíritu Santo en Pentecostés. Características: creencia en el Espíritu Santo, en carismas y dones espirituales del Nuevo Testamento: palabra de "sabiduría", don de curación, de profecía, de lenguas, de interpretación de las lenguas, etc. Carácter festivo de cultos y gran expresividad, manifiesto en las alabanzas. Rápida capacidad de conectarse con experiencias propias de la religiosidad popular, aun adaptándolas a sus singulares interpretaciones. En Argentina, dos momentos clave: 1. Período 1920- 1940: misiones de raíz estadounidense. 2. Década 1950: campaña del evangelista Tommy Hicks, relevancia en términos numéricos. Vínculos de Hicks con Perón. Impacto de su campaña en los líderes pentecostales argentinos. En Patagonia: corriente vinculada a grupos migratorios chilenos. Pentecostalismo extendido entre sectores populares.

Unión de las Asambleas de Dios/ Asambleas de Dios: denominación pentecostal más grande del mundo. Conjunto de denominaciones, unidas por principios fundamentales e historia común. Surgimiento 1924 aproximadamente, separación de los pentecostales unicitarios. Latinoamérica: mayor número de miembros, casi veintiocho millones de adherentes y más de doscientos siete mil iglesias. África: veintitrés millones de profesantes y ochenta y dos mil iglesias. 65\% protestantes en América Latina es considerado pentecostal, siendo de las Asambleas de Dios la mayor parte de estos. No tienen un cuerpo doctrinal ni gubernamental que las rija, marcadas diferencias dentro de la denominación, y dentro de una misma nación. Características: creencia: Trinidad y la divinidad plena del Hijo: "el Señor Jesucristo es el eterno Hijo de Dios"; nacimiento virginal, vida sin pecado, su obra sustitutiva en la cruz, resurrección, y su ascensión a la diestra del Padre. Sometimiento a toda la Escritura como la revelación máxima de Dios. Apego a la exposición de la Biblia y apertura al trabajo con otros movimientos y denominaciones (bautistas reformados). Bautismo del Espíritu Santo, posterior a la conversión. Don de lenguas. Énfasis en el evangelismo, lo que ha contribuido a su crecimiento explosivo. Servicios caracterizados por mucha emoción y exuberancia, llamativos para muchas culturas dentro del sur global. Sanidad divina parte integral del evangelio, considerándolo como una promesa del sacrificio de Cristo. En Argentina: Unión de las Asambleas de Dios, resulta de misioneros canadienses, norteamericanos, daneses y noruegos que decidieron asociarse hacia la década de 1940. En esa década la organización de las Asambleas radicadas en Estados Unidos comenzaron a enviar misioneros, de manera desordenada y poco sistemática. 1947, consolidación de iglesia más o menos estable en la Capital Federal. Ramas canadiense y norteamericana de las Asambleas de Dios, se asociaron conformando la Unión de las Asambleas de Dios. Fenómeno singular, acción de las iglesias pentecostales chilenas en el oeste argentino. Modelo institucionalmente planificado. 1944 creación de una iglesia argentina autónoma de la central chilena. 
Iglesias Cristianas Evangélicas sin denominación: surgieron a fines del siglo XX, se han expandido la mayoría de los países del mundo. EEUU se desarrollaron a partir de las décadas de 1980-1990, megaiglesias de ministerios, hoy denominados internacionales, que se han expandido a Latinoamérica, países europeos y algunos países africanos. Centroamérica número importante de fieles evangélicos que se reúnen en megaiglesias, que por sus características se las puede considerar pentecostales o neopentecostales. Sudamérica, caso sobresaliente es Brasil, en donde la Iglesia Universal del Reino de Dios ha logrado captar cifras importantes de fieles que dejaron el catolicismo para convertirse al evangelismo. Características del pentecostalismo o neopentecostalismo: reuniones con alabanzas efusivas, predicaciones que giran en torno a temáticas de la Segunda Venida de Cristo, la manifestación del Espíritu Santo, la prosperidad, entre otros temas. En Argentina: mitad de la década de 1980, más precisamente con el advenimiento de la democracia, expansión del evangelio. Penetró en las clases bajas y, hoy, consideradas populares. Grandes ciudades del país, barrios periféricos o ciudades del conurbano bonaerense, comenzaron a expandirse pequeñas iglesias que se nutrían de fieles convertidos en campañas evangelísticas. Década de 1990, empiezan a realizarse campañas evangelísticas masivas,se destacaron personajes como Carlos Anacondia, Claudio Freidson y Luis Palau. Siglo XXI, el evangelismo se propaga a todas las clases sociales, las mega iglesias se hacen visibles en el paisaje urbano de las principales ciudades del país.

A continuación, se presentan las definiciones de los conceptos claves utilizados en el presente trabajo:

Culto: o servicio en el Cristianismo evangélico, momento en que los creyentes se reúnen para alabar, adorar, hablar con Dios, recibir un sermón basado en la Biblia y periódicamente la comunión. Puede tener lugar con la Iglesia o con la familia. Las reuniones se pueden realizar los días de semana, pero los domingos tienen una connotación especial. Culto (evangelicalismo) (s.f). Recuperado de https://es.wikipedia.org/wiki/Culto_(evangelicalismo)

Evangélica, Iglesia: movimiento religioso internacional. El nombre ha sido utilizado por infinidad de organizaciones. Martín Lutero se refirió a las iglesias de la Reforma en Alemania como «Iglesia Evangélica» (actual nombre de la iglesia unificada de luteranos y reformados en ese país). Muchas denominaciones y numerosas iglesias independientes han llevado ese nombre, entre ellas la Iglesia Evangélica Alemana, la Iglesia Evangélica y Reformada, la Iglesia Evangélica de confesión luterana, la Iglesia Evangélica Pentecostal, etc. También la palabra «evangélica» o «evangélico» es frecuente en el nombre de denominaciones, como la Convención Evangélica «Los Pinos Nuevos»(Cuba), por citar ejemplo. Generalmente las iglesias evangélicas hacen énfasis en la justificación por fe. Entre los grupos más conservadores las «buenas nuevas» de salvación y el nuevo nacimiento son prédica constante. En algunos países como Estados Unidos, la palabra «evangélico» implica cierto grado de conservadurismo u ortodoxia tradicional dentro del protestantismo (Nuevo Diccionario de Religiones, Denominaciones y Sectas, 70).

Evangélicos: Miembros del movimiento o las iglesias evangélicas. En muchos países se denomina evangélicos a todos los protestantes. En otros, a los protestantes más conservadores. Muchos fundamentalistas se identifican como evangélicos, pero muchos evangélicos prefieren limitarse a esa designación y no se identifican como fundamentalistas. (Nuevo Diccionario de Religiones, Denominaciones y Sectas, 71). 
Fichero de Culto: documento que revela la inscripción de una denominación religiosa al Registro Nacional de Cultos, obligatorio por Ley 21.745/78, para las confesiones religiosas que no integren la Iglesia Católica Apostólica Romana. La pertenencia a dicho registro es una condición previa para su actividad en el territorio de la Nación Argentina. Esto significa la legalidad de la iglesia, facultad de actuar y abrir filiales en todo el territorio, posibilidad de agilizar trámites en Aduana y Migraciones, recibir subsidios estatales o privados, etc. Fichero de culto (s.f). http://www.estudioatr.com.ar/index.php?s=ficherodeculto

Iglesia: el vocablo "iglesia" proviene de la palabra en latín "ecclesia", la cual procede del

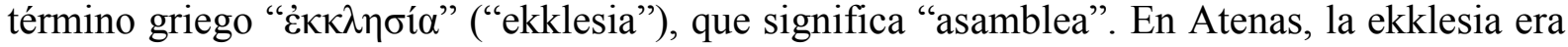
la asamblea de ciudadanos que se reunían para discutir asuntos públicos. Asimismo, ekkaleim en griego significa "llamada, invitación", es decir, se asocia esta palabra a la idea de una llamada a la participación. Término polisémico, pues en la actualidad se designa como iglesia, por un lado, al edificio público destinado al culto cristiano, donde se celebra la misa y otros servicios religiosos (bautismos, bodas), así como donde se practica la confesión y ceremonias litúrgicas de distinto tipo. Pero también, se entiende por Iglesia a la institución que representa al conjunto de personas que profesan la fe cristiana, al cuerpo de clérigos que forman parte de la jerarquía y se ocupan de los asuntos referidos a la práctica de esa fe, al igual que de sus relaciones con los demás componentes de la sociedad. En esta última acepción, se escribe con inicial mayúscula, lo mismo que las distintas ramas surgidas después de la Reforma luterana (Alemania, siglo XVI) y que derivó en el cisma de la Iglesia católica, originando así la Iglesia luterana, la Iglesia anglicana, la Iglesia presbiteriana y otras menores. Significado de Iglesia (2014, Diciembre 2). Recuperado de https://significado.net/iglesia/

Persona Jurídica: son todos los entes a los cuales el ordenamiento jurídico les confiere aptitud para adquirir derechos y contraer obligaciones para el cumplimiento de su objeto y los fines de su creación. Código Civil y Comercial de la Nación (s.f). Recuperado de http://servicios.infoleg.gob.ar/infolegInternet/anexos/235000-239999/235975/norma.htm\#7

Templo: (iglesia), lugar de la celebración y casa de la asamblea, de la comunidad. Del latín templum, designa un edificio sagrado. El Templo (iglesia) (2017, Enero 18). Recuperado de https://ofminmaculada.org/apuntes-liturgicos/1678-el-templo-iglesia

Uso del suelo: expresan las diferentes utilizaciones que se hacen del espacio en función de las necesidades y actividades de la población que vive y trabaja en la ciudad. (Zárate, 1984: 60). Se clasifican en: administrativo, comercial, residencial, industrial, otros.

\subsection{Resultados, Análisis y Discusión}

\section{Materiales y métodos}

A los efectos de poder identificar, caracterizar y cartografiar manifestaciones culturales religiosas relacionadas al culto evangélico en la SFR de Río Gallegos, se llevó a cabo una investigación exploratoria, por ser un tema poco estudiado en Río Gallegos y descriptiva, porque se describe y caracteriza a las iglesias evangélicas de la SFR.

En primer lugar, se realizó la búsqueda y selección de bibliografía pertinente para esta investigación, luego se procedió a ordenarla según su pertenencia a tres grupos teóricos distintos, siendo estos Geografía Cultural y Geografía de las Religiones, Culto evangélico y Segunda Franja Residencial. De los campos antes mencionados, se investigó sobre la 
Geografía Cultural y de las Religiones en general, y específicamente sobre la formación histórico-territorial de Río Gallegos con el fin de identificar el área conocida como Segunda Franja Residencial. Asimismo, se investigó sobre la presencia histórica de denominaciones evangélicas en Santa Cruz y en Río Gallegos.

En segundo lugar, se confeccionó cartografía temática sobre la ciudad y la SFR a través del programa Qgis Essen.

En tercer lugar, se realizó una salida de campo, la misma constó de tres instancias. La primera fue de trabajo en gabinete. Se diseñó una planilla en hoja de cálculo, en la cual se relevaron las variables de las unidades de análisis, siendo estas cada uno de los templos a localizar; se tomó en cuenta el nombre, denominación, localización (latitud y longitud), domicilio, entre otras. También en esta etapa, se realizó una búsqueda preliminar a través de redes sociales y por otros sitios de internet pertinentes, sobre los templos evangélicos presentes en la SFR.

La segunda instancia fue la salida de campo propiamente dicha. El día viernes 5 de julio de 2019, por la mañana comenzó la misma, se completó la planilla de relevamiento. Este recorrido se realizó con un chofer de la UARG, quien realizó el recorrido de cada una de las subdivisiones de la SFR. El becario completó la planilla de relevamiento, la directora de la beca, Prof. Norambuena tomó fotografías de los templos encontrados y la codirectora, Lic. Cáceres ayudó con el relevamiento. La salida finalizó con éxito el mismo dia por la tarde, con las cuatro subdivisiones recorridas.

La última instancia, fue el trabajo en gabinete con la información obtenida en la salida de campo. Se tabulo, ordenó y agrupó la información obtenida, con el fin de ser interpretada para arribar a los resultados. Asimismo, se obtuvieron las coordenadas geográficas mediante el programa Google Earth a fin de confeccionar la cartografía temática correspondiente en QGis.

En cuarto lugar, el becario trabajó en la formulación de los resultados, discusión y conclusión, los que fueron supervisados por la directora y codirectora de la beca.

Por último, se trabajó con la redacción del informe de la beca, según el formato solicitado, Informe Científico Técnico UNPA.

\section{Resultados}

A continuación, en relación a la caracterización de las denominaciones evangélicas en la SFR, se presenta la Tabla $\mathrm{N}^{\circ} 1$, en la que se encuentran todas las edificaciones relacionadas a este culto, producto del relevamiento realizado y representadas en la Figura 5: 


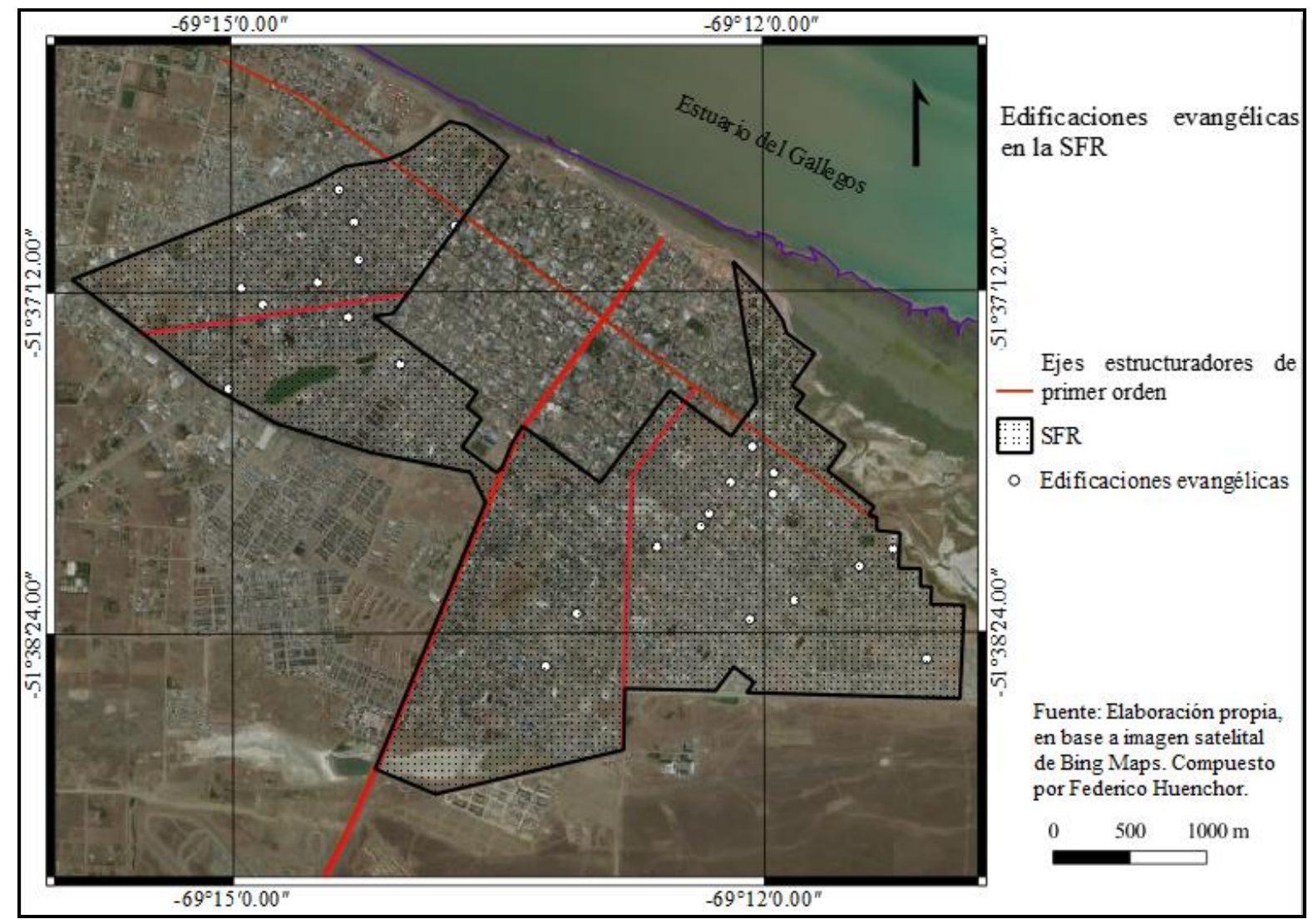

Figura 5. Localización de las edificaciones evangélicas en la SFR

Cabe aclarar, que de las denominaciones evangélicas presentes en Río Gallegos, no se identificó ningún templo Bautista en la SFR.

Culto Evangélico de la SFR en Río Gallegos

\begin{tabular}{|l|c|c|c|c|c|}
\hline \multicolumn{1}{|c|}{ Nombre } & Denominación & $\begin{array}{c}\text { Localización } \\
\text { Lat. S } \\
\text { Long.O }\end{array}$ & Subdivisión & $\begin{array}{c}\text { Uso del } \\
\text { suelo } \\
\text { anterior }\end{array}$ & $\begin{array}{c}\text { Anexo o } \\
\text { principal }\end{array}$ \\
\hline $\begin{array}{l}\text { Iglesia Evangélica } \\
\text { Asamblea de Dios en } \\
\text { el Chaco filial } \\
\text { Macedonia Aike }\end{array}$ & $\begin{array}{c}\text { Asamblea } \\
\text { de Dios }\end{array}$ & $\begin{array}{c}-51^{\circ} 37^{\prime} 7^{\prime \prime} \\
-69^{\circ} 14^{\prime} 03^{\prime \prime}\end{array}$ & $\begin{array}{c}\text { Occidental- } \\
\text { sur }\end{array}$ & Comercial & Anexo \\
\hline $\begin{array}{l}\text { Iglesia Pentecostal } \\
\text { Dios es Amor }\end{array}$ & Pentecostal & $\begin{array}{l}-51^{\circ} 38^{\prime} 05^{\prime \prime} \\
-69^{\circ} 12^{\prime} 36^{\prime \prime}\end{array}$ & $\begin{array}{c}\text { Oriental- } \\
\text { norte }\end{array}$ & Religioso & Anexo \\
\hline $\begin{array}{l}\text { Iglesia Cristiana } \\
\text { Hijos del Altísimo }\end{array}$ & SD & $\begin{array}{l}-51^{\circ} 37^{\prime} 05^{\prime \prime} \\
-69^{\circ} 14^{\prime} 17^{\prime \prime}\end{array}$ & $\begin{array}{c}\text { Occidental- } \\
\text { norte }\end{array}$ & Residencial & Anexo \\
\hline $\begin{array}{l}\text { Iglesia Cristiana } \\
\text { Hijos del Altísimo }\end{array}$ & SD & $\begin{array}{l}-51^{\circ} 37^{\prime} 07^{\prime \prime} \\
-69^{\circ} 14^{\prime} 31^{\prime \prime}\end{array}$ & $\begin{array}{c}\text { Occidental- } \\
\text { norte }\end{array}$ & Religioso & Anexo \\
\hline $\begin{array}{l}\text { Asociación } \\
\text { Evangélica Iglesia del } \\
\text { Señor Apostólica }\end{array}$ & Apostólica & $\begin{array}{l}-51^{\circ} 38^{\prime} 01^{\prime \prime} \\
-69^{\circ} 12^{\prime} 21^{\prime \prime}\end{array}$ & $\begin{array}{c}\text { Oriental- } \\
\text { norte }\end{array}$ & Religioso & Principal \\
\hline $\begin{array}{l}\text { Iglesia Evangélica } \\
\text { Pentecostal }\end{array}$ & Pentecostal & $-51^{\circ} 36^{\prime} 57^{\prime \prime}$ & $\begin{array}{c}\text { Occidental- } \\
\text { norte }\end{array}$ & Religioso & Principal \\
\hline $\begin{array}{l}\text { Iglesia Evangélica } \\
\text { Pentecostal Argentina } \\
\text { Dios te Ama }\end{array}$ & Pentecostal & $-69^{\circ} 14^{\prime} 18^{\prime \prime} 37^{\prime} 11^{\prime \prime}$ & $\begin{array}{c}\text { Occidental- } \\
\text { norte }\end{array}$ & Religioso & Principal \\
\hline
\end{tabular}




\begin{tabular}{|c|c|c|c|c|c|}
\hline $\begin{array}{l}\text { Iglesia Espíritu Santo } \\
\text { y Fuego }\end{array}$ & Pentecostal & $\begin{array}{l}-51^{\circ} 37^{\prime} 55^{\prime \prime} \\
-69^{\circ} 11^{\prime} 58^{\prime \prime}\end{array}$ & $\begin{array}{l}\text { Oriental- } \\
\text { norte }\end{array}$ & Comercial & Principal \\
\hline $\begin{array}{l}\text { Iglesia Cristiana } \\
\text { Pentecostal Jesús está } \\
\text { Aquí }\end{array}$ & Pentecostal & $\begin{array}{l}-51^{\circ} 38^{\prime} 10^{\prime \prime} \\
-69^{\circ} 11^{\prime} 27^{\prime \prime}\end{array}$ & $\begin{array}{l}\text { Oriental- } \\
\text { norte }\end{array}$ & Residencial & Principal \\
\hline $\begin{array}{lr}\text { Iglesia } & \text { Metodista } \\
\text { Pentecostal Argentina }\end{array}$ & $\begin{array}{c}\text { Pentecostal } \\
\text { Metodista }\end{array}$ & $\begin{array}{l}-51^{\circ} 37^{\prime} 17^{\prime \prime} \\
-69^{\circ} 14^{\prime} 20^{\prime \prime}\end{array}$ & $\begin{array}{c}\text { Occidental- } \\
\text { sur }\end{array}$ & Religioso & Principal \\
\hline $\begin{array}{l}\text { Iglesia Evangélica } \\
\text { Pentecostal Misionera }\end{array}$ & $\begin{array}{c}\text { Pentecostal } \\
\text { Misionera }\end{array}$ & $\begin{array}{l}-51^{\circ} 36^{\prime} 50^{\prime \prime} \\
-69^{\circ} 14^{\prime} 24^{\prime \prime}\end{array}$ & $\begin{array}{l}\text { Occidental- } \\
\text { norte }\end{array}$ & Religioso & Principal \\
\hline $\begin{array}{l}\text { Iglesia del Buen } \\
\text { Pastor. Unión de las } \\
\text { Asambleas de Dios }\end{array}$ & $\begin{array}{l}\text { Asamblea } \\
\text { de Dios }\end{array}$ & $\begin{array}{l}-51^{\circ} 37^{\prime} 14^{\prime \prime} \\
-69^{\circ} 14^{\prime} 49^{\prime \prime}\end{array}$ & $\begin{array}{l}\text { Occidental- } \\
\text { norte }\end{array}$ & Religioso & Principal \\
\hline $\begin{array}{l}\text { Iglesia Evangélica } \\
\text { Unión Pentecostal }\end{array}$ & Pentecostal & $\begin{array}{l}-51^{\circ} 38^{\prime} 17^{\prime \prime} \\
-69^{\circ} 11^{\prime} 50^{\prime \prime}\end{array}$ & $\begin{array}{c}\text { Oriental- } \\
\text { norte }\end{array}$ & Religioso & Principal \\
\hline $\begin{array}{l}\text { Centro Cristiano } \mathrm{La} \\
\text { Red }\end{array}$ & SD & $\begin{array}{l}-51^{\circ} 36^{\prime} 58^{\prime \prime} \\
-69^{\circ} 13^{\prime} 44^{\prime \prime}\end{array}$ & $\begin{array}{l}\text { Occidental- } \\
\text { norte }\end{array}$ & Religioso & Principal \\
\hline $\begin{array}{l}\text { Misión Evangélica } \\
\text { Argentina para Cristo }\end{array}$ & Misionera & $\begin{array}{l}-51^{\circ} 37^{\prime} 32^{\prime \prime} \\
-69^{\circ} 15^{\prime} 01^{\prime \prime}\end{array}$ & $\begin{array}{l}\text { Occidental- } \\
\text { sur }\end{array}$ & Recreativo & Principal \\
\hline $\begin{array}{ll}\text { Iglesia } & \text { Sendas } \\
\text { Eternas } & \end{array}$ & SD & $\begin{array}{l}-51^{\circ} 37^{\prime} 51^{\prime \prime} \\
-69^{\circ} 11^{\prime} 56^{\prime \prime}\end{array}$ & $\begin{array}{l}\text { Oriental- } \\
\text { norte }\end{array}$ & Comercial & Principal \\
\hline $\begin{array}{l}\text { Iglesia Adventista del } \\
\text { Séptimo Día }\end{array}$ & Adventista & $\begin{array}{l}-51^{\circ} 37^{\prime} 58^{\prime \prime} \\
-69^{\circ} 12^{\prime} 18^{\prime \prime}\end{array}$ & $\begin{array}{c}\text { Oriental- } \\
\text { norte }\end{array}$ & Residencial & Principal \\
\hline $\begin{array}{l}\text { Federación Asamblea } \\
\text { Cristiana }\end{array}$ & $\begin{array}{l}\text { Asamblea } \\
\text { de Dios }\end{array}$ & $\begin{array}{l}-51^{\circ} 37^{\prime} 44^{\prime \prime} \\
-69^{\circ} 12^{\prime} 04^{\prime \prime}\end{array}$ & $\begin{array}{c}\text { Oriental- } \\
\text { norte }\end{array}$ & Religioso & Principal \\
\hline $\begin{array}{lcc}\text { Iglesia } & \text { Hijos } & \text { del } \\
\text { Altísimo Templo } & \\
\end{array}$ & SD & $\begin{array}{l}-51^{\circ} 38^{\prime} 06^{\prime \prime} \\
-69^{\circ} 11^{\prime} 16^{\prime \prime}\end{array}$ & $\begin{array}{c}\text { Oriental- } \\
\text { norte }\end{array}$ & Religioso & Principal \\
\hline Iglesia de Dios & SD & $\begin{array}{l}-51^{\circ} 37^{\prime} 52^{\prime \prime} \\
-69^{\circ} 12^{\prime} 11^{\prime \prime}\end{array}$ & $\begin{array}{c}\text { Oriental- } \\
\text { norte }\end{array}$ & Religioso & Principal \\
\hline $\begin{array}{l}\text { Comunidad Cristiana } \\
\text { Dios es mi Refugio }\end{array}$ & SD & $\begin{array}{l}-51^{\circ} 38^{\prime} 29^{\prime \prime} \\
-69^{\circ} 11^{\prime} 05^{\prime \prime}\end{array}$ & $\begin{array}{c}\text { Oriental- } \\
\text { norte }\end{array}$ & Religioso & Principal \\
\hline $\begin{array}{ll}\text { Iglesia } & \text { Asociación } \\
\text { Unión } & \text { Evangélica } \\
\text { Argentina } & \\
\end{array}$ & SD & $\begin{array}{l}-51^{\circ} 38^{\prime} 21^{\prime \prime} \\
-69^{\circ} 12^{\prime} 05^{\prime \prime}\end{array}$ & $\begin{array}{l}\text { Oriental- } \\
\text { norte }\end{array}$ & Religioso & Principal \\
\hline $\begin{array}{l}\text { Iglesia } \quad \text { Cristiana } \\
\text { Evangélica Encuentro } \\
\text { con Dios }\end{array}$ & SD & $\begin{array}{l}-51^{\circ} 38^{\prime} 19^{\prime \prime} \\
-69^{\circ} 13^{\prime} 03^{\prime \prime}\end{array}$ & Oriental-sur & Religioso & Principal \\
\hline $\begin{array}{lr}\text { Iglesia } & \text { Alianza } \\
\text { Cristiana y Misionera } \\
\text { Argentina }\end{array}$ & Misionera & $\begin{array}{l}-51^{\circ} 38^{\prime} 31^{\prime \prime} \\
-69^{\circ} 13^{\prime} 14^{\prime \prime}\end{array}$ & Oriental-sur & Religioso & Principal \\
\hline
\end{tabular}

Tabla $N^{\circ}$ 1. Fuente: salida de campo, elaboración propia. SD: sin denominación.

Del relevamiento, primero se obtuvieron las coordenadas geográficas a fin de confeccionar la cartografía temática correspondiente y luego, se registraron un total de 24 edificios con las siguientes características:

Sector Oriental-norte: concentra el mayor número de templos evangélicos, con doce en total; los templos Sin Denominación son los más representativos con un total de cinco, seguidos por los Pentecostales con cuatro, otro rasgo significativo es que posee los únicos templos Apostólico y Adventista en toda la SFR. Además, posee un templo de la Unión de las Asambleas de Dios/Asamblea de Dios. Sólo un templo es anexo de otra Iglesia, los restantes son templos principales, y sólo dos templos presentan el uso del suelo comercial 
anteriormente. También es importante mencionar que un templo también cuenta con una radio y una escuela.

Sector Oriental-sur: es el sector con menor cantidad de denominaciones, una Misionera y una Sin Denominación, ambas comparten las características de ser templos principales y de presentar el uso del suelo religioso anteriormente.

Sector Occidental-norte: presenta siete templos y los Sin Denominación son los más numerosos con tres, seguidos por la denominación Pentecostal con tres y uno comparte la denominación Misionera y un templo es de la Unión de las Asambleas de Dios/Asamblea de Dios. Sólo dos templos son anexos, los cinco restantes son principales, y solo uno presenta uso del suelo residencial anterior.

Sector Occidental-sur: presenta pocos templos, son de tres denominaciones distintas, una Unión de las Asambleas de Dios/Asamblea de Dios, una Metodista que a su vez es Pentecostal, es decir comparte denominación y una Misionera, este templo anteriormente fue un comercio.

Algunas iglesias identificadas visibilizan la personería jurídica, registro nacional de culto y fichero de culto, pero son escasas por lo que este dato no se incluyó en la planilla final detallada.

En el caso de la SFR, las iglesias que tienen o no una denominación, poseen, en algunos casos templos principales y en otros son anexos o contienen escuelas y radios. Es así que dos poseen una radio y una posee tanto una radio como una escuela. Este último caso es la Iglesia Cristiana Hijos del Altísimo, que cuenta con una radio, una escuela con todos los niveles actualmente, no se encuentra habilitada por las autoridades del Estado provincial para funcionar-, un anexo en el barrio Nuestra Señora del Carmen y un templo principal en el barrio Gaucho Rivero.

Se identificó sólo una iglesia perteneciente a la denominación Adventista, este es el caso de la Iglesia Adventista del Séptimo Día, edificio que alberga un templo principal, en el barrio Belgrano. El uso del suelo identificado anteriormente es el residencial, hoy se distingue el religioso, por la cartelería indicativa de la denominación de la iglesia. Posee dinamismo en la red social Facebook.

De la denominación Apostólica, sólo se identificó y localizó una iglesia, la misma se encuentra en el barrio Belgrano. Es la Asociación Evangélica Iglesia del Señor Apostólica. Esta hace visible el registro nacional de culto y la personería jurídica. A simple vista el uso del suelo es religioso, no se evidencia un uso anterior. Es un templo principal.

Perteneciente a la denominación Metodista, se identificó y localizó una sola iglesia. Esta es la Iglesia Metodista Pentecostal Argentina, siendo un templo principal. Esta posee dinamismo en la red social Facebook. Es visible cartelería con el registro nacional de culto y la personería jurídica. Esta iglesia también se identifica con la denominación Pentecostal. El uso del suelo identificado es el religioso.

Iglesias de la denominación Misionera, se identificaron y localizaron tres. Estas son la Iglesia Alianza Cristiana y Misionera Argentina, que se encuentra en el barrio Centenario, la Iglesia Evangélica Pentecostal Misionera, ubicada en el barrio Nuestra Señora del Carmen y la 
Misión Evangélica Argentina para Cristo, ubicada en la calle Banciella entre Gendarmería Nacional y Rodríguez en el barrio Gregores. Todas son templos principales, pero la segunda, evidencia uso del suelo anterior como residencial. La Iglesia Evangélica Pentecostal Misionera tiene visible el fichero de culto y la personería jurídica y también se la puede relacionar con la denominación Pentecostal. La Misión Evangélica Argentina para Cristo anteriormente poseía uso del suelo recreativo, perteneció durante décadas a diferentes locales bailables. Esta iglesia es activa en la red social Facebook, y despertó el debate por el cambio de uso del suelo de recreativo a religioso.

Las iglesias cuya denominación es Pentecostal, son las que tienen mayor presencia territorial en la SFR, en este caso se identificaron las siguientes: Iglesia Evangélica Pentecostal Misionera, Iglesia Evangélica Pentecostal, Iglesia Metodista Pentecostal Argentina, Iglesia Evangélica Pentecostal Argentina, Iglesia Espíritu Santo y Fuego, Iglesia Pentecostal Dios es Amor, Iglesia Cristiana Pentecostal Jesús esta Aquí e Iglesia Evangélica Unión Pentecostal. La mayoría de estas iglesias se encuentran en los barrios Belgrano, Gaucho Rivero y Nuestra Señora del Carmen. Solo una iglesia es un anexo de un templo principal, esta es la Iglesia Pentecostal Dios es Amor localizada en el barrio Belgrano, el resto son todos templos principales. Varias tienen dinamismo en la red social Facebook. La Iglesia Evangélica Pentecostal Argentina posee personería jurídica y fichero de culto visibles. La Iglesia Cristiana Pentecostal Jesús está Aquí presenta uso del suelo residencial, es claramente un departamento en el barrio Gaucho Rivero; en el cartel que indica el nombre de la iglesia.

De la Unión de las Asambleas de Dios/Asambleas de Dios, se identificaron y localizaron la Iglesia Evangélica Asamblea de Dios en el Chaco, filial Macedonia Aike ubicada en el barrio Fátima, es un templo principal que anteriormente tenía uso del suelo comercial; esta iglesia es activa en la red social Facebook. También se encontró la iglesia Federación Asamblea Cristiana, en el barrio Belgrano, es un templo principal. Por último, dentro de esta denominación se identificó a la Iglesia del Buen Pastor. Unión de las Asambleas de Dios es un templo principal en el barrio Nuestra Señora del Carmen, activo en la red social Facebook.

De las Iglesias Cristianas Evangélicas sin denominación se pueden mencionar a la Iglesia Cristiana Hijos del Altísimo (barrio Gaucho Rivero, templo principal, radio y antes escuela; barrio Nuestra Señora del Carmen, anexo), Iglesia Sendas Eternas, Iglesia de Dios, Comunidad Cristiana Dios es mi Refugio, Iglesia Asociación Unión Evangélica Argentina e Iglesia Cristiana Evangélica Encuentro con Dios. Como se mencionó anteriormente, la Iglesia Cristiana Hijos del Altísimo posee un templo principal con radio y, en años anteriores, escuela con todos los niveles educativos y un anexo. La Iglesia Sendas Eternas comparte un local comercial con uso del suelo comercial recreativo (salón de cumpleaños), en el barrio Belgrano. La mayoría de estas iglesias son principales.

Finalmente, tres iglesias poseen radios, estas son Iglesia Cristiana Hijos del Altísimo, Misión Evangélica Argentina para Cristo y la Asociación Evangélica Iglesia del Señor Apostólica.

\section{Discusión}

Las iglesias pertenecientes al culto evangélico en la SFR, fueron identificadas, localizadas y caracterizadas. De las iglesias relacionadas al culto evangélico en la ciudad de Río Gallegos, todas las denominaciones identificadas se encuentran presentes territorialmente en la SFR a excepción de la Bautista. Por otra parte, varias iglesias no son solo de una denominación, algunas de estas la comparten, por ejemplo, Iglesia Evangélica Pentecostal Misionera; en este 
caso, es tanto es Pentecostal como Misionera o el caso de la Iglesia Metodista Pentecostal Argentina, que es tanto Metodista como Pentecostal.

La iglesia cristiana sin denominación Hijos del Altísimo, es la que posee mayor cantidad de edificios en la SFR, el templo principal, anexo, radio y escuela. Se localiza en el barrio Belgrano (templo principal, radio y escuela) y en el barrio Nuestra Señora del Carmen.

Varias iglesias son activas en la red social Facebook, como la Iglesia Sendas Eternas, la Iglesia Espíritu Santo y Fuego, las Iglesias Hijos del Altísimo, la Misión Evangélica Argentina para Cristo, por nombrar algunas.

La legislación vigente sobre zonificación en Río Gallegos contempla el uso del suelo religioso, dentro de la categoría conocida con el nombre de "servicio a la comunidad", relacionándose así con los templos pertenecientes al culto evangélico en la SFR.

En cuanto a las denominaciones identificadas, localizadas y caracterizadas (Tabla 2), se obtuvo el siguiente detalle:

\begin{tabular}{|l|c|}
\hline \multicolumn{1}{|c|}{ Denominación } & Templos \\
\hline Adventista & 1 \\
\hline Apostólica & 0 \\
\hline Bautista & 1 \\
\hline Metodistas & 3 \\
\hline Misionera & 8 \\
\hline Pentecostal & 3 \\
\hline Unión de las Asambleas de Dios/Asambleas de Dios & 7 \\
\hline Sin denominación & 1 \\
\hline
\end{tabular}

Tabla $\mathrm{N}^{\mathrm{o}}$ 2: Templos en la SFR de las denominaciones identificadas, localizadas y caracterizadas. Fuente: elaboración propia.

De la identificación, localización y caracterización de las iglesias pertenecientes al culto evangélico según los sectores dentro de la SFR, se puede mencionar y representar (Figura 6) lo siguiente: 


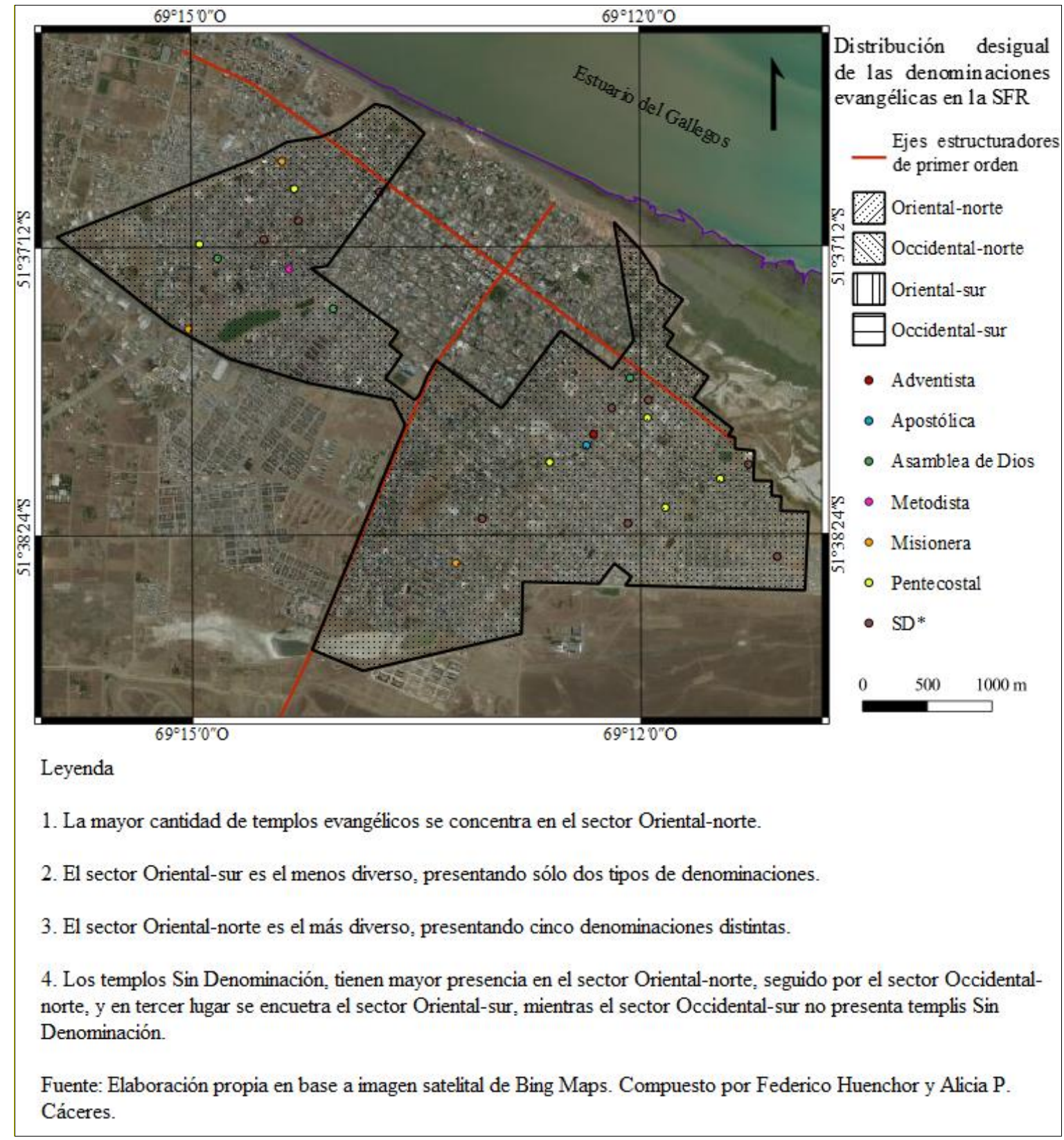

Figura 6. Distribución desigual de las denominaciones evangélcias en la SFR

Sector Occidental Norte: 3 iglesias Pentecostales (1 comparte la Misionera), 1 de la Unión de las Asambleas de Dios/Asambleas de Dios y 3 iglesias Sin Denominación.

Sector Oriental Norte: 1 iglesia Adventista, 1 Apostólica, 1 Unión de las Asambleas de Dios/Asambleas de Dios, 4 Pentecostales y 5 iglesias Sin Denominación.

Sector Oriental Sur: 1 iglesia Misionera y 1 Sin Denominación.

Sector Occidental Sur: 1 iglesia Misionera, 1 Metodista (comparte la Pentecostal) y 1 iglesia Unión de las Asambleas de Dios/Asambleas de Dios.

La presencia del culto evangélico en Santa Cruz y principalmente en Río Gallegos, ha tenido desarrollo durante todo el siglo XX. El siglo XXI se caracteriza por la aparición de Iglesias 
Cristianas Evangélicas sin denominación. Estas iglesias poseen una organización, formalidad e influencia en el territorio que se da de manera incremental.

Finalmente, en cuanto a las iglesias evangélicas en la SFR, se evidencia una clara relación entre la localización de las mismas y la historia del surgimiento de estas en Río Gallegos. Los inmigrantes chilenos que llegaron a la ciudad durante todo el siglo $\mathrm{XX}$, han transportado su cultura y dentro de esta, sus prácticas religiosas. Los barrios donde estos inmigrantes se asentaron a partir de la década de 1960, fueron principalmente el barrio Belgrano y el Nuestra Señora del Carmen. Si se entrelazan la localización de buena parte de las iglesias en la SFR con la historia de la inmigración chilena en Río Gallegos, se puede afirmar que estas dos variables coinciden.

\section{CONCLUSIONES}

En relación a la hipótesis planteada al comienzo de la Beca de Investigación, las manifestaciones culturales religiosas relacionadas al culto evangélico, se identificaron, localizaron y caracterizaron en la Segunda Franja Residencial de Río Gallegos, por tanto fue posible, en efecto, estudiar estas manifestaciones culturales religiosas, en el marco de la Geografía de las Religiones.

En relación a los dos objetivos planteados, el primero relevar y analizar bibliografía específica sobre la Geografía Cultural y la Geografía de las Religiones en particular y, el segundo identificar, caracterizar y cartografiar manifestaciones culturales religiosas relacionadas al culto evangélico en la SFR de Río Gallegos, se ha cumplido con los mismos.

\section{RECOMENDACIONES}

Se recomienda a los interesados en la temática, tener en cuenta el presente trabajo desde lo metodológico, además de los resultados.

\section{AGRADECIMIENTOS}

Se agradece a la abogada Carla Tellez por su contribución en la conformación del marco conceptual, puntualmente en los términos legales. 


\section{ANEXO}

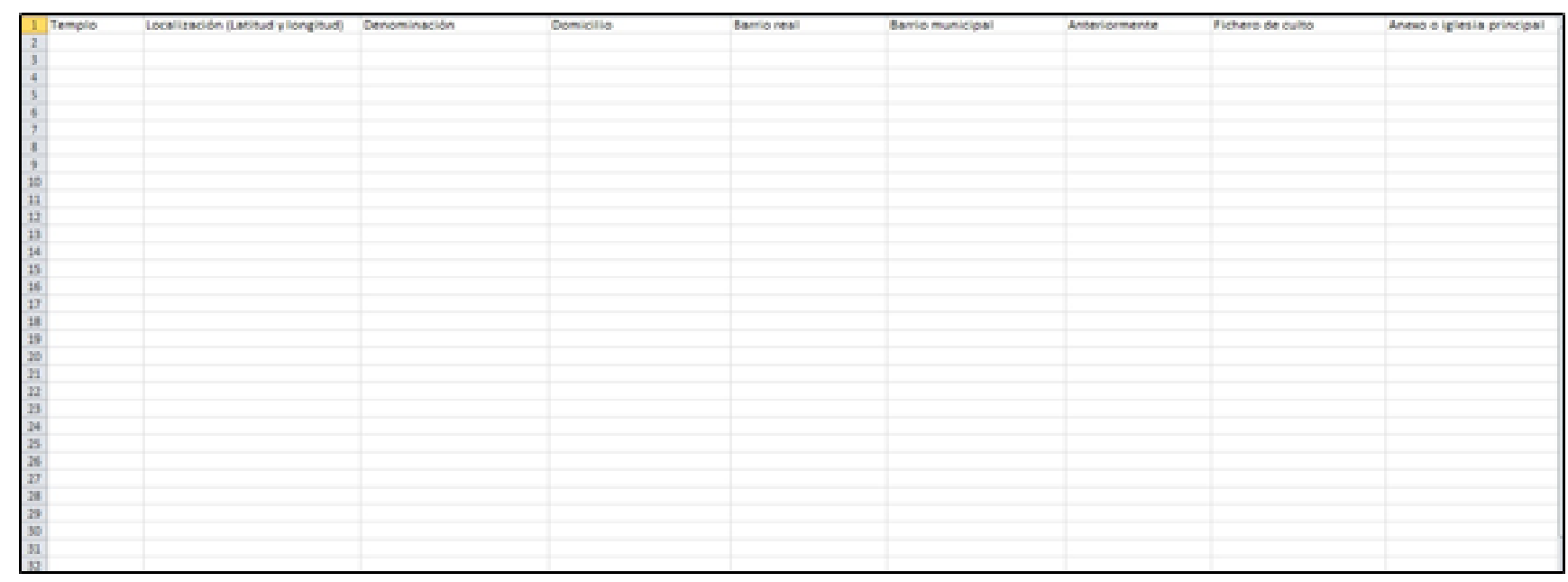

Planilla de relevamiento para la salida de campo.

\section{Lista de referencias}

AMPUERO C. (2011): La veneración del Nazareno de Caguach en la ciudad de Río Gallegos, Patagonia Austral Argentina. Trabajo final del seminario Filosofía y Teología del Doctorado en Geografía, Universidad del Salvador. Buenos Aires. Inédito.

CÁCERES A. P. (2019) Subdivisión interna de la Segunda Franja Residencial de Río Gallegos. Inédito.

CÁCERES A. P., GARCÍA A. N. (2004) Diferenciación Interna del Espacio Geográfico de Río Gallegos: Estudio Preliminar. Revista del Instituto de Investigaciones Geográficas de la Patagonia. IGEOPAT. Año III. $\mathrm{N}^{\circ}$ 3. UNP. páginas. 11-36. Comodoro Rivadavia. Chubut.

CÁCERES A., SEGOVIA STANOSS M., SOTO J., NORAMBUENA M., FRÍAS P., AMPUERO C. (2016) Posición Geográfica de Río Gallegos en la Patagonia Austral". Congreso Internacional de Geografía. $77^{a}$ Semana de Geografía "Geografía del Bicentenario”. San Miguel de Tucumán (Tucumán). Actas. Páginas. 47- 60. 14 páginas.

CARBALLO C. (2008) Buenos Aires y las creencias religiosas: un mapa inestable. Revista Universitaria de Geografia. 29-45.

CARBONELLI M. A., MOSQUEIRA M. A. (2008) "Luis Palau en Argentina": Construcción mediática del cuerpo evangélico, disputa por el espacio público y nuevas formas de territorialidad". Enfoques XX, $2: 65-87$.

CLAVAL P. (1999) Los fundamentos de la geografía cultural. Doc. Anál. Geogr. 34. Páginas $25-40$. 
GLOSARIO DE TÉRMINOS GEOGRÁFICOS (Geografía Humana) (2005). Universitat Jaume I Castellón.

HIDAlGO R., ARENAS F., PAULSEN A., TIMOFEEW T., HENRIQUEZ P. (2012). Localización de la infraestructura Católica, dinámicas socioterritoriales y geografía de las religiones: el caso del Área Metropolitana de Santiago de Chile. Pontificia Universidad Católica de Chile, Santiago, Chile. Vol 38, No 115 | septiembre 2012. Revista EURE ISSN digital 0717-6236.

IBARRA M. (s.f.) La Iglesia Metodista y su vínculo en la conformación de los primeros organismos de Derechos Humanos.

LAGO L. (s.f.) Protestantes y Pentecostales en Comodoro Rivadavia. Cruces entre religión, procesos migratorios e identidades étnicas en los grupos bóers y chilenos (siglo XX).

LÓPEZ LEVI L. (2010) “La geografía cultural en México: entre viejas y nuevas tendencias" en: Hiernaux Daniel (director) Construyendo la geografía humana. Universidad Autónoma Metropolitana-Iztapalapa / Anthropos. ISBN: 978-84-7658-962-5. Páginas. 205-228.

MANCILLA H. (2009) Núcleo formativo del campo evangélico: heterogeneidad identitaria en Río Gallegos (Santa Cruz) hacia fines de 1950. En Actas XII Jornadas Interescuelas/Departamentos de Historia. Departamento de Historia, Facultad de Humanidades y Centro Regional Universitario Bariloche. Universidad Nacional del Comahue, San Carlos de Bariloche. Argentina.

MIGUEZ D. (s.f.) El Protestantismo Popular en Argentina. Las Lógicas de Expansión del Pentecostalismo Durante el siglo XX. Publicado en: Anuario del Instituto de Estudios Histórico Sociales No 14, páginas 163-201.

MUNICIPALIDAD DE RÍO GALLEGOS (2012), Departamento de Actividad Parlamentaria, Zonificación. Legislación vigente. Ordenanza N 3259: Reglamentación.

NORAMBUENA M. (2019). Caracterización de las denominaciones evangélicas en Río Gallegos. Inédito.

NUEVO DICCIONARIO DE RELIGIONES, DENOMINACIONES Y SECTAS. http://www.medioscan.com/pdf/religionesysectas.pdf

SANTARELLI S., CAMPOS M. (2011) Geografía de las Religiones, Espacios Locales y subjetividad. Una nueva mirada en la enseñanza universitaria. Revista Geográfica de América Central, vol. 2, julio-diciembre, 2011, páginas. 1-19 Universidad Nacional Heredia, Costa Rica.

STEFANONI P. (2018, Mayo 27) Iglesias evangélicas, un poder que crece en América Latina. La Nación. https://www.lanacion.com.ar/opinion/iglesias-evangelicas-unpoder-que-crece-en-america-latina-nid2137761 
TEC-LÓPEZ R. (2018) ¿Quiénes son los neopentecostales? Una aproximación a la conceptualización del fenómeno religioso. XIX Jornadas sobre Alternatividades Religiosas en América Latina "Itinerarios y nuevas cartografías religiosas en América Latina" Santiago de Chile, 14-17 de noviembre de 2018.

WYNARCZYK H. (s.f.) Los evangélicos en la sociedad argentina, la libertad de cultos y la igualdad. Dilemas de una modernidad tardía.

ZARATE A. (1984). El mosaico urbano. Organización interna y vida en las ciudades. Madrid, Editorial Cincel. 